\title{
DFT Study on the Conformational and Vibrational Properties of 3'-Deoxycytidine and Its Analogues
}

\author{
Marawan Ahmed ${ }^{1}$, Aimin $\mathrm{Yu}^{2}$ \& Feng Wang ${ }^{1}$ \\ 1 eChemistry Laboratory, Faculty of Life and Social Sciences, Swinburne University of Technology, Melbourne, \\ Victoria, Australia \\ ${ }^{2}$ Faculty of Life and Social Sciences, Swinburne University of Technology, Melbourne, Victoria, Australia \\ Correspondence: Marawan Ahmed, Faculty of Life and Social Sciences, Swinburne University of Technology, \\ Melbourne, Victoria 3122, Australia. Tel: 61-3-9214-8785. E-mail: mmahmed@swin.edu.au
}

Received: January 4, 2013 Accepted: April 3, 2013 Online Published: April 25, 2013

doi:10.5539/ijc.v5n2p68 URL: http://dx.doi.org/10.5539/ijc.v5n2p68

\begin{abstract}
Impact of saturation of the sugar $\mathrm{C}\left(3^{\prime}\right)=\mathrm{C}\left(4^{\prime}\right)$ bond of acytidine nucleoside derivative, 3', 4'-didehydro-3'-deoxycytidine (I) is revealed usingsimulated vibrational spectra, with respect to $3^{\prime}$-deoxycytidine. The density functional theory based calculations found that the $\mathrm{C}\left(3^{\prime}\right)=\mathrm{C}\left(4^{\prime}\right) \mathrm{double}$ bondrestricts the sugar flexibility and affects the sugar-base intramolecular hydrogen bond network. For $3^{\prime}$-dC, two minimal energy conformers are identified on the potential energy surface. The first conformer (IIA) takes anO4'-endo and gauche-gauche (gg) orientation whereas the second (IIB) has a C3'-exo and gauche-trans (gt) orientation in gas phase. The two conformers which have been observed previously in the crystal structure are separated by a low energy barrier. The carbon double bond in the sugar moiety of I confines the pseudorotation of the pentagon ring to be significantly flatter than that of the sugar ring in IIA and IIB. The simulated vibrational spectra, both in gas phase and in solutions, report such structural caused spectral changes with red and blue vibrational frequency shifts. The firsthydration shell of 3'-dC has been also investigated applying hybrid QM/MM molecular dynamic simulation.
\end{abstract}

Keywords: 3'-deoxycytidine, intramolecular interactions, IR spectroscopy,solvent effects, hydration shell

\section{Introduction}

Cytidine analogues are an important class of chemotherapeutic agents used mainly as anti-tumoror anti-viralagents(Galmarini, Jordheim, \& Dumontet, 2003; Schinazi et al., 2002). They may interfere with certain nuclear enzymes, acting as enzyme inhibitors, or be incorporated in a growing nucleic acid chain causing cell death (Galmarini, Mackey, \& Dumontet, 2002). On the other hand, resistance to current anticancer and antiviral agents are emerging and wide-spreading, which requires insight understanding of the molecular behaviour of the drugs including their detailed structures as DNA building blocks (Fernández-Calotti, Colomer, \& Pastor-Anglada, 2011; Clercq, 2004). Previous studies have reported that anti-HIV activity of the nucleoside antibiotics drugs depends upon the ribose conformer (Torrance et al., 2001), usually with an unsaturated sugar ring and lack of the $\mathrm{C} 2$ '-OH or $\mathrm{C} 3$ '-OH groups.It has been also shown that conformational changes may impact the anti-viral or the anti-tumor activity (Rodriguez et al., 1994; Wang, 2000). This may somehow guide the process of drug design by, for example, the synthesis of conformationally locked nucleoside analogues to facilitate the interaction with their target enzymes (Rodriguez et al., 1994; Wang, 2000).

A pair of didehydrodeoxycytidine (DDC) cytidine isomer derivativeanti-cancer drugs with an unsaturated $\mathrm{C}=\mathrm{C}$ bond in the sugar was synthesized (Torrance et al., 2001), which were later named as 1',2'-didehydro-2'-deoxycytidine (1',2'-D3C) and 3',4'-didehydro-3'-deoxycytidine (3',4'-D3C) (Wang, 2007). The cytidine (DDC) isomers differ by the positions of the $\mathrm{C}=\mathrm{C}$ bond in the sugar ring (Torrance et al., 2001). However, it was even unable to separate the isomers at their synthesis (Torrance et al., 2001). To resolve this issue, theoretical simulation and modelling are required to proceed in this direction. Wang (2007) first

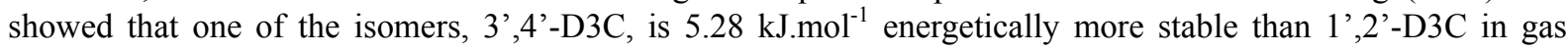
phase, due to their different conformational structures. Then the isomers are studied through saturation of the $\mathrm{C}=\mathrm{C}$ double bond. One such isomer produces 2'-deoxycytidine (2'-dC) (Ahmed \& Wang, 2013; Selvam, Chen, \& Wang, 2010) and the 3',4'-D3C isomer produces 3'-deoxycytidine (3'-dC, II). Here, II is known to be an 
efficient antibacterial, anti-parasitic andanti-tumor agent (Karthe et al., 1997) and a useful reversible inhibitor of DNA replication (Brooks, 1978).

Nucleosides and their analogues possess a very complex network of intramolecular H-bonds (Selvam, Chen, \& Wang, 2010; Chen, Selvam, \& Wang, 2010; Arnott \& Hukins, 1969). The extent of these H-bond interactions determines the overall properties of the molecules such as geometries, dipole moments and vibrational properties and also linked to the drug potency (Chidangil \& Mishra, 1997; Niwas et al., 1994). The present geometrical study concentrates on the base-sugar orientation $(\chi, \gamma)$ (Altona \& Sundaralingam, 1972; Bell, Hecht, \& Barron, 1997 ) and the sugar puckering $\left(P, v_{\max }\right)$ (Sun et al., 2004), as these structural parameters play an important role in nucleoside chemistry (Sundaralingam, 1975). Also, Infrared (IR) spectroscopy has been used as an important tool to studymolecular structures and intramolecular H-bond networks of nucleoside analogues (Selvam, Chen, \& Wang, 2010; Chen, Selvam, \& Wang, 2010) with respect to red (proper) or blue (improper) shift of the spectra (Ahmed \& Wang, 2013). The present study aims at investigating the sugar-base orientation changes caused by the saturation of the $\mathrm{C}=\mathrm{C}$ bond in $3^{\prime}, 4^{\prime}$-didehydro-3'-deoxycytidine $\left(3^{\prime}, 4^{\prime}\right.$-D3C, i.e., I) which yields 3'-deoxycytidine (3'-dC, II). The changes are probed using IR spectroscopy. The study also aims at exploring the conformational landscape of 3'- $\mathrm{dC}$ whose crystal structure has identified the existence of two conformers stabilized by several inter- and intra-molecular H-bonds (Karthe et al., 1997). The major difference between these two conformers was the orientation around the $\mathrm{C}\left(5^{\prime}\right)-\mathrm{O}\left(5^{\prime}\right)$ exocyclic arm, where one of them belongs to the gauche-gauche(gg)(IIA) category of conformation, the other one belongs to the gauche-trans(gt)(IIB) category.

For studying the solvent effect, several solvents of various polarities, benzene $(\varepsilon=2.27)$, tetrahydrofuran (THF, $\varepsilon$ $=7.43$ ), tetrahydrothiophene-s,s-dioxide (THT, $\varepsilon=43.96)$ and water $(\varepsilon=78.36$ ), are employed to investigate the changes in different solvation media and applying the implicit solvent model Polarized Continuum Model (PCM). We have also further investigated the first hydration shell of 3'-dC using explicit solvent MD simulations applying the hybrid QM/MM method and utilizing the DFTB method for the QM subsystem. Results obtained by this method range from excellent to good agreement with other highly accurate wavefunction and/or DFT based models. DFTB geometrical data are in particular with excellent agreement with higher level calculations (Yang et al., 2007). The method also provides some improvement via the introduction of third order dispersion as well as other corrections (Yang et al., 2008; Dolgonos et al., 2009; Gaus, Cui, \& Elstner, 2011; Elstner et al., 2001). These modifications allow DFTB to perform very well for proton affinities calculations, DNA bases stacking and several more (Yang et al., 2007; Kaminski et al., 2012).

\section{Methods and Computational Details}

Chemical structures and atomic numbering of 3',4'-didehydro-3'-deoxycytidine (I) and 3'-deoxycytidine (IIA and IIB) are presented in Figure 1a.As indicated previously (Ahmed \& Wang, 2013; Selvam, Chen, \& Wang, 2010; Chen, Selvam, \& Wang, 2010; Sun et al., 2004; Ning et al., 2008; Selvam, Vasilyev, \& Wang, 2009), rotations of the glycosyl $\chi$ angle and the $\gamma$ angle, combined with the sugar puckering produce a number of nucleoside conformers. The most stable conformation of nucleosides I and II are identified using a fully relaxed two-dimensional (2D) potential energy surface scan, i.e., $\mathrm{V}(\chi, \gamma)$, based on the density functional theory (DFT) based B3LYP/6-31G model, where the glycosyl $\chi$ angle and the $\gamma$ angle are defined as $\chi=$ $\angle \mathrm{O}\left(4^{\prime}\right)-\mathrm{C}\left(1^{\prime}\right)-\mathrm{N}(1)-\mathrm{C}(2)$ and $\gamma=\angle \mathrm{C}\left(3^{\prime}\right)-\mathrm{C}\left(4^{\prime}\right)-\mathrm{C}\left(5^{\prime}\right)-\mathrm{O}\left(5^{\prime}\right)$, respectively. The obtained energy minimum structures of $\mathbf{I}$ and $\mathbf{I I}$ on the potential energy surfaces are further optimized using the B3LYP/6-311++G** model with a larger basis set. No imaginary frequencies are found for both nucleosides in the harmonic frequency calculations, indicating that the energy minimum structures obtained are true minima rather than saddle points. Sugar puckering (Ning et al., 2008; Kilpatrick, Pitzer, \& Spitzer, 1947; Duffy, 2008; Yang et al., 2007) of the nucleosides, which is determined by the pseudo rotational phase angle $\left(\mathrm{P}^{\circ}\right)$ and the amplitude of puckering $\left(v_{\max }\right)$, is obtained using the PROSIT tool (Sun et al., 2004). 

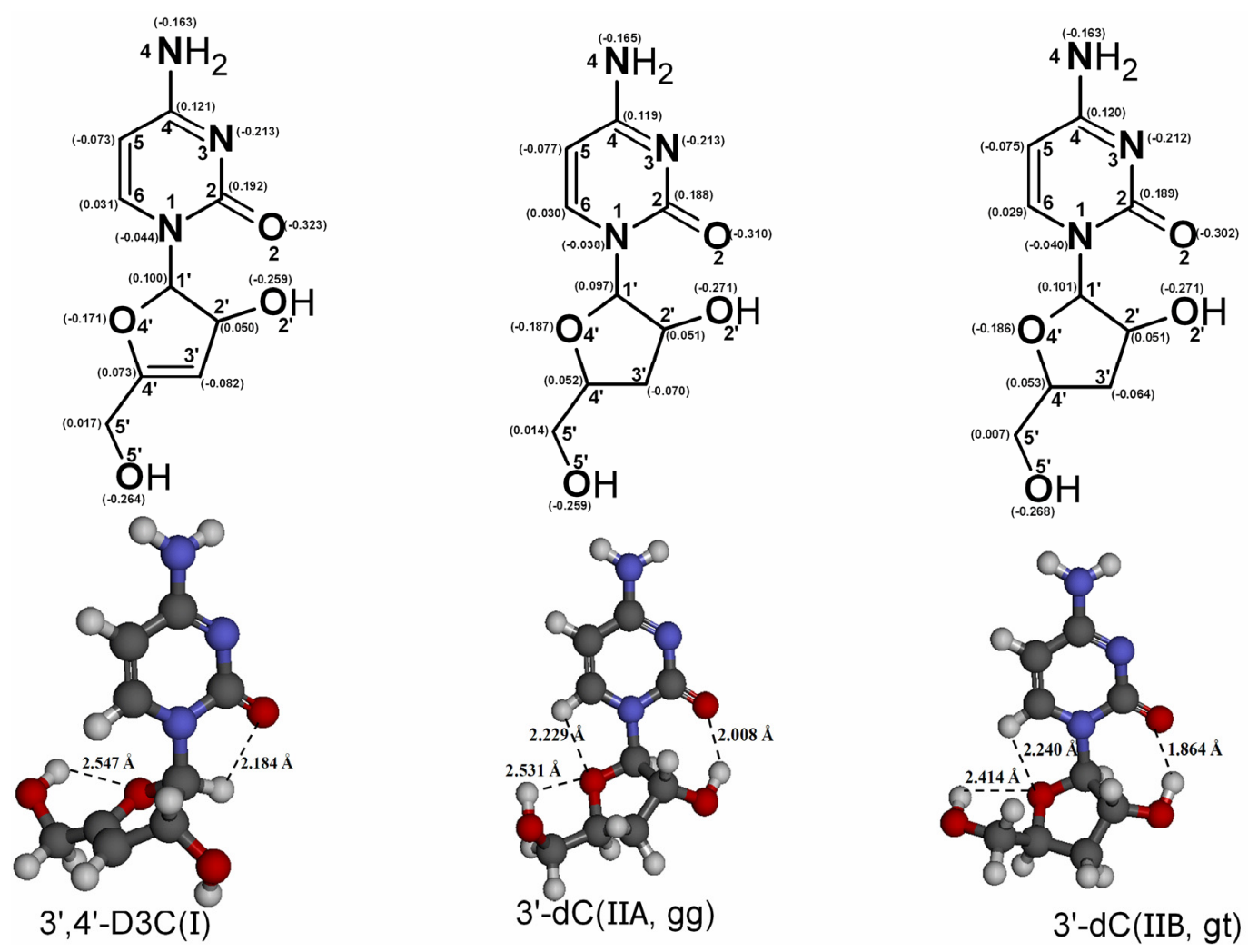

(a)

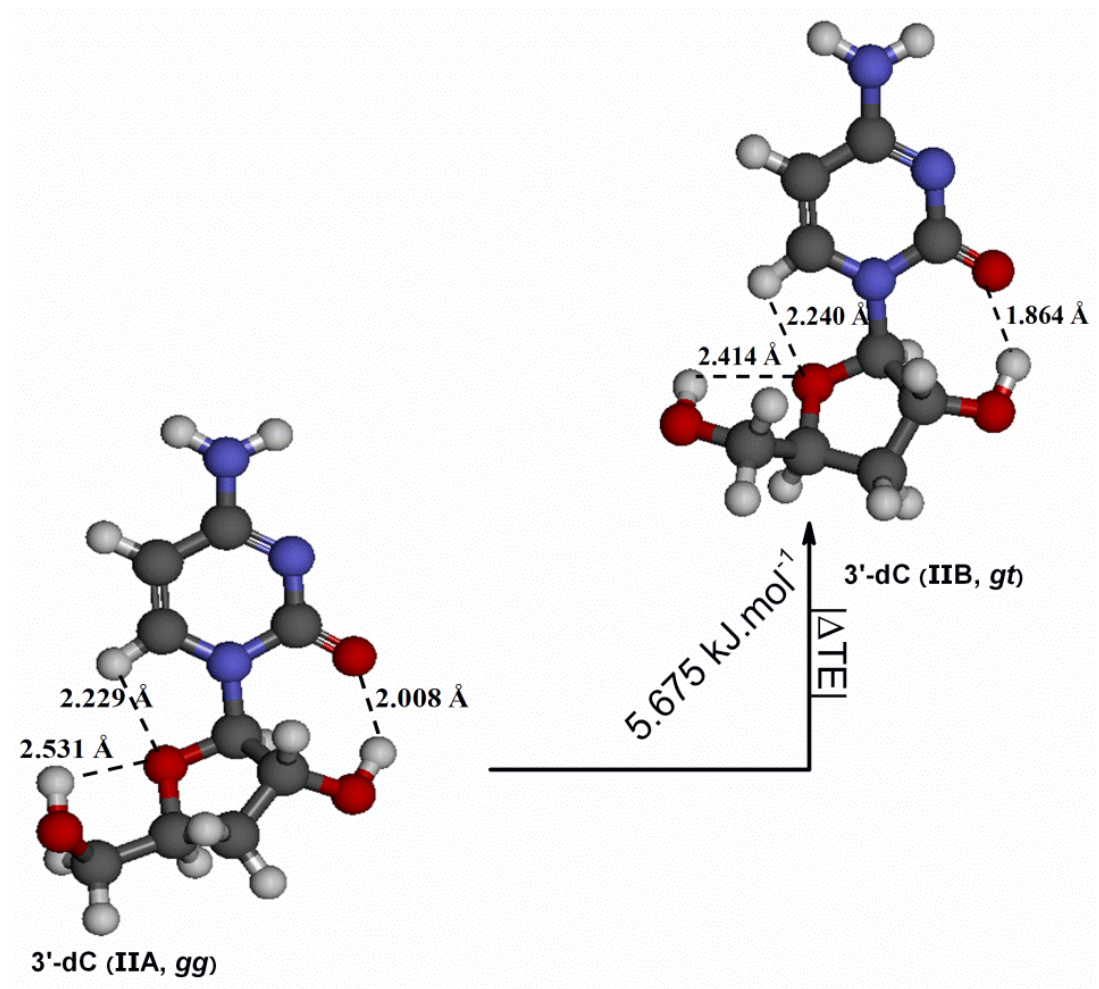

(b)

Figure 1. (a) The 2D and 3D structures with the Hirshfeld charges in parentheses of 3', 4'-didehydro-3'-deoxycytidine (3',4'-D3C, i.e., I) and the two conformers of 3'-deoxycytidine (IIA ( $\mathbf{g g})$ and IIB $(\boldsymbol{g t})$ ) and (b) the two 3'-dC conformers (IIA and IIB)showing the calculated total energy difference 
The IR spectra and other properties of the nucleosides are calculated using the B3LYP/6-311++G** model. Four solvents with various polarities, such as benzene $(\varepsilon=2.27)$, tetrahydrofuran (THF, $\varepsilon=7.43$ ), tetrahydrothiophene-s,s-dioxide (THT, $\varepsilon=43.96)$ andwater $(\varepsilon=78.36)$ are employed to study solvent effect using the polarizable continuum model (PCM) (Cossi et al., 2003). The Hirshfeld charges (Selvam, Vasilyev, \& Wang, 2009; Davidson \& Chakravorty, 1992) and condensed Fukui functions $\left(f^{-}\right)$(Selvam, Vasilyev, \& Wang, 2009; Fukui, 1982; Yang \& Mortier, 1986; Parr \& Yang, 1984) are calculated using the LB94/et-pVQZ model (Chen \& Wang, 2009). Here the et-pVQZ basis set is an even tempered-polarized valence quadruple-zeta slater type basis set(Chong et al., 2004). The DFT based LB94 model (van Leeuwen \& Baerends, 1994) has been applied to produce the density for Hirshfeld charge and Fukui function calculations in the present study, as this model predicts localised core ionization potentials well for a number of DNA bases (Thompson et al., 2009; Zhu, Wang, \& Ivanova, 2009) and nucleosides (Selvam, Vasilyev, \& Wang, 2009; Chen \& Wang, 2009).

Hydrogen bonds of the nucleosides (Selvam, Chen, \& Wang, 2010; Chen, Selvam, \& Wang, 2010) are indicated using the distances between a hydrogen atom $(\mathrm{H})$, and an oxygen atom $(\mathrm{O})$, or a nitrogen atom $(\mathrm{N})$ of the compounds, using a simple cut-off criterion of $2.80 \AA$ (Huang, Yu, \& Lin, 2006).

The calculations were performed using Gaussian 09 (G09) (Frisch et al., 2009) computational chemistry package and the Amsterdam Density Functional (ADF) computational chemistry program (te Velde et al., 2001).

For hydration shell calculation, the optimized nucleoside was immersed in a cubic box of water with a buffer region from the boundary of $20 \AA$. QM/MM dynamics is performed using the dispersion corrected DFTB Hamiltonian for the QM system composed of 3'-dC only. The MM subsystem was treated using the flexible $\mathrm{SPC} / \mathrm{FW}$ water model as implemented in AMBER and applying the ff99SB force field (te Velde et al.; Wu, Tepper, \& Voth, 2006; Lindorff-Larsen et al., 2010; Case et al., 2005; Salomon-Ferrer, Case, \& Walker, 2012). The system was first minimized then heated to $300 \mathrm{~K}$ in the NVT ensemble for 2 psthen relaxed classically for 2 $\mathrm{ns}$ in the NPT ensemble. Again the system is relaxed in the NPT ensemble but applying the DFTB Hamiltonian for the nucleoside only subsystem and for $750 \mathrm{ps}$ and extended by another $1 \mathrm{~ns}$ production simulation. In all stages, periodic boundary conditions are applied and a small time step of $0.5 \mathrm{fs}$ was utilized to integrate the equations of motion. For long range electrostatic interactions, particle mesh Ewald (PME) (Darden, York, \& Pedersen, 1993) was utilized and truncated after $15 \AA$. The DFTB Hamiltonian is known to give excellent structural results for nucleosides (Kubař et al., 2007).

\section{Results and Discussion}

\subsection{Geometric Properties}

Studying geometrical properties of nucleosides and their analogues is important, as this may affect the interactions with their macromolecular targets (Harte Jr. et al., 1991; Choi et al., 2003). This may have certain implications on some fields such as drug design. Table 1 compares the globally minimized geometric parameters of I and II with available results obtained from experiment and previous studies (Wang, 2007; Selvam, Chen, \& Wang, 2010; Karthe et al., 1997). The results are in good agreement with the available computational data and experimental crystal structures. As commonly observed in most pyrimidine nucleosides and their analogues, the minimal structures are generally belonging to the anti category of conformation, which refers to the orientation of the sugar ring relative to the base moiety, and is defined by the $\chi$ angle $\left(=\angle \mathrm{O}\left(4^{\prime}\right)-\mathrm{C}\left(1^{\prime}\right)-\mathrm{N}(1)-\mathrm{C}(2)\right)$. The Potential Energy Surface (PES) of each nucleoside has been also explored for other conformational structures that may also be populated. For $\mathbf{I}$, the second most stable conformer was belonging to the syn category of conformers $\left(\chi=59.90^{\circ}\right)$. For II, two favourable conformational structures have been identified with a total

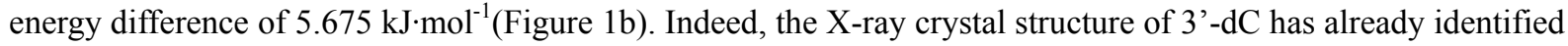
the existence of two conformers, the first one was belonging to the gauche-gauche (gg) category and the second one was belonging to the gauche-trans (gt) category of conformations. The gauche and trans notations refer to the orientation of the exocyclic $\mathrm{C}\left(5^{\prime}\right)-\mathrm{O}\left(5^{\prime}\right)$ arm, and this is defined by two angles; the $\omega$ $\left(\angle \mathrm{O}\left(5^{\prime}\right)-\mathrm{C}\left(4^{\prime}\right)-\mathrm{C}\left(5^{\prime}\right)-\mathrm{O}\left(5^{\prime}\right)\right)$ and the $\gamma\left(\angle \mathrm{C}\left(3^{\prime}\right)-\mathrm{C}\left(4^{\prime}\right)-\mathrm{C}\left(5^{\prime}\right)-\mathrm{O}\left(5^{\prime}\right)\right)$ angles. In the experimental paper, the authors used the letters $\mathbf{A}$ and $\mathbf{B}$ to define the $\boldsymbol{g} \boldsymbol{g}$ and the $\boldsymbol{g t}$ conformational structures, respectively, and we will follow the same convention, so, IIA is the $\mathbf{g g}$ conformer and IIB is the gt conformer. For I, we will limit our discussion to the globally identifiedanti conformer. For comparison purposes, we will use bracket to denote the IIB properties.

As shown in Table 1, the double bond $\mathrm{C}\left(3^{\prime}\right)=\mathrm{C}\left(4^{\prime}\right)$ of $3^{\prime}, 4^{\prime}-\mathrm{D} 3 \mathrm{C}$ (I) makes the sugar moiety more rigid and flat compared to the sugar of II. For example, I exhibits an unusual $\mathrm{C} 1^{\prime}$-endo conformation with the pseudorotationalphase angle $\mathrm{P}$ of $322.89^{\circ}$ and a puckering amplitude $v_{\max }$ of 10.41 whereas the saturated derivative, $3^{\prime}$-dC (II), possesses an $\mathrm{O}^{\prime}$ '-endo (C3'-exo) conformations with the pseudorotational phase of $73.12^{\circ}$ 
$\left(182.91^{\circ}\right)$ and the amplitude of $v_{\max }$ of $38.23(27.05)$.

The $\mathrm{C}=\mathrm{C}$ bond also contributes to the changes in the sugar-base orientation apparently (Table 1). For example, $\mathbf{I}$ possess an anti-periplanar geometry with $\chi=-111.64^{\circ}$, which enhances the intramolecular H-bond, $\mathrm{C}\left(1^{\prime}\right)-\mathrm{H} \cdots \mathrm{O}(2)(2.184 \AA)$ and hereby stabilizes the structure. On the other hand, both II conformers possess a pure antiorientation with a $\chi=-176.31^{\circ}\left(-174.14^{\circ}\right)$, whichresults in a pair of strong H-bonds, i.e., $\mathrm{O}\left(2^{\prime}\right)-\mathrm{H} \cdots \mathrm{O}(2)$ bond which is given by $2.008 \AA(1.864 \AA$ ) and $\mathrm{C}(6)-\mathrm{H} \cdots \mathrm{O}(4$ ') bond given by $2.229 \AA$ (2.240 $\AA$ ) (as shown by the "spider webs" in Figure 1a).

For II and as mentioned before, the X-ray crystal structure study identified two conformers to co-exist in the same crystal, A and B. In the present study, the two conformers are indeed located, with the $\boldsymbol{g} \boldsymbol{g}$ conformer (IIA) being more stable by $5.675 \mathrm{~kJ}^{-\mathrm{mol}^{-1}}$ than the gt conformers (IIB) (Table 1, Figure 1b). The X-ray structure was obtained from the Cambridge Structural Database (CSD) (van, 2006). B3LYP results are cross-checked against MP2 results at the same level of theory $\left(6-311++\mathrm{G}^{* *}\right)$. Each conformer is stabilized by a number of intramolecular H-bonds (see above) as shown in Figure 1b. Some discrepancies between the experimentally determined crystal structures and the gas phase structures are expected and may be linked to the presence of intermolecular interactions and crystal packing forces. As noted previously(Altona \& Sundaralingam, 1972), such packing forces may overcome certain geometrical disadvantages and/or shift the equilibrium geometry in gas phase and/or solution to another form that has a lower incidence of occurrence in crystal. For example, the experimental $\chi$ angle of the $g g$ conformer is given by $-142.4^{\circ}$ which is almost $34^{\circ}$ (ignoring signs) less than the corresponding value in gas phase).

Both conformers (IIA and IIB) possess a pure anti configuration in gas phase/crystal structure with the $\chi$ angle of about $-176^{\circ}$ and $-174.14^{\circ}$ in gas phase and $-142.4^{\circ}$ and $-172.10^{\circ}$ in the crystal structure, respectively. However, the discrepancy in the stabilization energy ( $I \Delta \mathrm{TEI}$ of $5.675 \mathrm{~kJ} \cdot \mathrm{mol}^{-1}$ ) is attributed to the differences of the orientation of the exocyclic arm $\left(\mathrm{C}_{4}, \mathrm{C}_{5}\right.$, $)$ and is estimated using the $\gamma$ angle. In contrast to the IIA conformer which has a gauche conformation with a $\gamma$ angle of $54.01^{\circ}$ in gas phase and $60.7^{\circ}$ in crystal, IIB possess a trans configuration with ay angle of $179.06^{\circ}$ in gas phase and $173.70^{\circ}$ in crystal and is less stabilized. For the $\omega$ angle, both molecules have a comparable values and lie within the same category (gauche). The use of solvent does not affect either the geometries or the stability orders of I or both the II conformers. For more information see supplementary materials (S1 and S2 tables).

\subsection{Other Molecular Properties}

Hirshfeld charges $\left(\mathrm{Q}^{\mathrm{H}}\right)$ are important indicators of atomic site dependent activities. Figure 1a also gives the atomic Hirshfeld charges on the atoms other than hydrogens calculated using the LB94/et-pVQZ model. In general, for the non-hydrogen atoms, nitrogens and oxygens are negatively charged whereas carbons are either negatively (when not directly bond with $\mathrm{N}$ or $\mathrm{O}$ ) or positively charges (when directly bond with $\mathrm{N}$ or $\mathrm{O}$ ), depending on their positions in the nucleoside. Saturation of the $C\left(3^{\prime}\right)=C\left(4^{\prime}\right)$ in I doesn't affect the charge distribution of all sites of the nucleoside evenly: the apparent $\mathrm{Q}^{\mathrm{H}}$ changes happen almost locally in the vicinity of $\mathrm{C}\left(3^{\prime}\right)=\mathrm{C}\left(4^{\prime}\right)$ of sugar except for $\mathrm{O}(2)$ of the keto oxygen. For example, apparent changes $\mathrm{Q}^{\mathrm{H}}$ are on the $\mathrm{C}\left(3^{\prime}\right)$, $\mathrm{C}\left(4^{\prime}\right), \mathrm{C}\left(5^{\prime}\right), \mathrm{O}(2), \mathrm{O}\left(2^{\prime}\right)$ and $\mathrm{O}\left(4^{\prime}\right)$ sites when the $\mathrm{C}\left(3^{\prime}\right)=\mathrm{C}\left(4^{\prime}\right)$ become $\mathrm{C}\left(3^{\prime}\right)-\mathrm{C}\left(4^{\prime}\right)$. All the nitrogen and oxygen sites exhibit negative charges, which serve as electron donor to attract $\mathrm{H}$ atom to form $\mathrm{H}$-bonds.

For the two 3'- $\mathrm{dC}$ conformers, it appears that no significant changes are taking place and the most affected atomic site by this local conformational change is the $\mathrm{O}\left(5^{\prime}\right)$ site, which possess a $\mid 0.009$ a.u. $\mid$ more negative charge on IIA than in IIB. 
Table 1. Selected gas phase geometric parameters of the nucleoside derivatives 3',4'-D3C (I) and 3'-dC (IIA), the corresponding parameters of the IIB conformers are in brackets in comparison with some available theoretical and experimental results

\begin{tabular}{|c|c|c|c|c|c|}
\hline Parameters & 3',4'-D3C I & & 3'-dC IIA ( IIB) & & \\
\hline & This work $^{\mathrm{a}}$ & Wang $^{b}$ & This work & $\begin{array}{c}\text { Selvam et } \\
\text { al. }^{\mathrm{c}}\end{array}$ & Exp. $^{d}$ \\
\hline $\mathbf{R}_{5}(\AA)$ & 7.229 & 7.230 & $7.494(7.486)$ & 7.49 & 7.43 \\
\hline $\mathbf{R}_{\mathbf{6}}(\AA)$ & 8.287 & 8.300 & $8.253(8.249)$ & 8.26 & 8.20 \\
\hline$\angle \mathrm{C}_{(4)}-\mathrm{C}_{(5)}-\mathrm{C}_{(6)}\left({ }^{\mathrm{o}}\right)$ & 116.34 & & $116.57(116.52)$ & & \\
\hline$\angle \mathrm{C}_{(5)}-\mathrm{C}_{(6)}-\mathrm{N}_{(1)}\left({ }^{\mathrm{o}}\right)$ & 121.38 & & $120.88(121.29)$ & & \\
\hline$\angle \mathbf{C}_{\left(1^{\prime}\right)^{\prime}}-\mathbf{N}_{(1)}-\mathbf{C}_{(6)}\left({ }^{0}\right)$ & 120.56 & & $122.87(122.53)$ & & \\
\hline $\begin{array}{c}\chi=\angle \mathbf{O}_{\left(4^{\prime}\right)}-\mathbf{C}_{\left(1^{1}\right)}-\mathbf{N}_{(1)}-\mathbf{C}_{(2)} \\
\left({ }^{0}\right)\end{array}$ & -111.64 & -109.51 & $-176.312(-174.14)$ & -168.79 & $-142.4(-172.10)$ \\
\hline $\begin{array}{c}\gamma=\angle \mathbf{C}_{\left(3^{\prime}\right)}-\mathbf{C}_{\left(4^{\prime}\right)^{-}}-\mathbf{C}_{\left(5^{\prime}\right)^{\prime}}-\mathbf{O}_{\left(5^{\prime}\right)} \\
\left({ }^{\mathbf{O}}\right)\end{array}$ & 121.82 & -5.66 & $54.01(179.06)$ & 171.45 & $60.7(-173.70)$ \\
\hline $\begin{array}{c}\omega=\angle \mathbf{O}_{\left(4^{\prime}\right)^{\prime}}-\mathbf{C}_{\left(4^{\prime}\right)^{\prime}}-\mathbf{C}_{\left(5^{\prime},\right.}-\mathbf{O}_{\left(5^{\prime}\right)} \\
\left({ }^{\mathbf{O}}\right)\end{array}$ & -58.08 & & $-62.87(60.77)$ & & $-56.8(69.1)$ \\
\hline$P\left({ }^{0}\right)$ & 322.89 & 322.97 & $73.12(182.91)$ & 195.53 & $21.6(20.20)$ \\
\hline$v_{\max }$ & 10.41 & 9.54 & $38.23(27.05)$ & 28.75 & \\
\hline$<\mathbf{R}^{2}>$ (a.u.) & 3877.258 & 4132.690 & $4053.738(3893.222)$ & 3780.810 & \\
\hline$\mu(D)$ & 5.581 & 5.540 & $6.007(5.274)$ & 4.89 & \\
\hline Total Energy $\quad\left(\mathbf{E}_{\mathbf{h}}\right)$ & -814.950204 & & $\begin{array}{l}-816.185409 \\
(-816.183247)^{\mathrm{e}}\end{array}$ & & \\
\hline ZPE (kcal.mol ${ }^{-1}$ ) & 130.502 & 130.345 & $146.206(146.037)$ & 147.390 & \\
\hline T.E. $+\mathrm{ZPE}\left(\mathrm{E}_{\mathrm{h}}\right)$ & -814.742236 & -814.750306 & $-815.952414(-815.950523)$ & & \\
\hline Sugar type & C1'-endo & C1'-endo & O4'-endo (C3'-exo) & C3'-exo & C3'-endo( C3'-endo) \\
\hline
\end{tabular}

${ }^{a} \mathrm{~B} 3 \mathrm{LYP} / 6-311++\mathrm{G}^{* *}$, the local minimal structure $(\mathrm{gt})$ is in brackets.

${ }^{\mathrm{b}} \mathrm{B} 3 \mathrm{LYP} / 6-311++\mathrm{G}^{* *}$, see (Wang, 2007).

${ }^{\mathrm{c}}$ B3LYP/6-31G*, see (Selvam, Chen, \& Wang, 2010).

${ }^{\mathrm{d}}$ Crystal phase, see (P. Karthe, N. Gautham, A. Kumar et al., 1997), both the experimentally identified conformers are mentioned.

${ }^{\mathrm{e}} \Delta \mid$ T.E. $\mid=5.675 \mathrm{~kJ} . \mathrm{mol}-1$. 


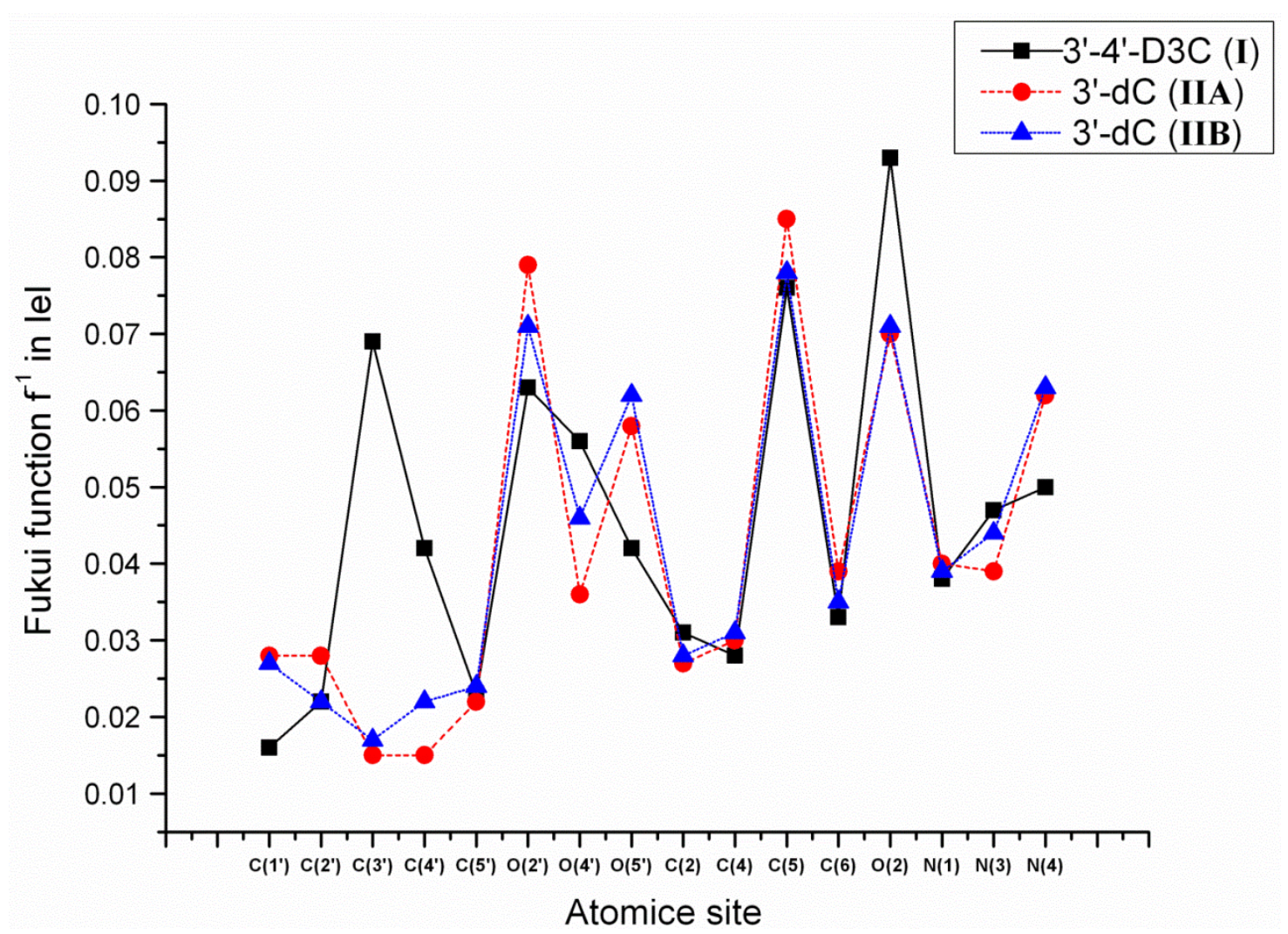

Figure 2. Comparison of the atomic site based condensed Fukui function of I, IIA and IIB

Study of the reactivity of nucleoside analogues provides informationassociated with their potency (Galmarini, Mackey, \& Dumontet, 2001). Condensed Fukui function $\left(f^{-}\right)$, which describes and assess the tendency of an atomic site to undergo an electrophilic attack (Fukui, 1982; Kolandaivel, Praveena, \& Selvarengan, 2005), are therefore, calculated and given in Figure 2. The solid line represents the Fukui functions of I, whereas the dashed and dotted lines stand for the Fukui functions of IIA andIIB, respectively. It is obvious in Figure 2 that all the sites constituting the sugar ring (left hand side) changes more or less except for the C(5') site. On the contrary, most of the sites in the base moiety have only minor changes except for $\mathrm{O}(2)$ and $N(4)$. Some sites are deactivated by the $\mathrm{C}=\mathrm{C}$ bond saturation, the apparent ones are the $\mathrm{C}\left(1^{\prime}\right), \mathrm{O}\left(5^{\prime}\right)$ and $\mathrm{N}(4)$. It's noteworthy to stress that the $\mathrm{O}\left(5^{\prime}\right)$ is the phosphorylation (activation) site of the nucleoside analogue (Alcolea-Palafox \& Iza, 2012), and the more active this site the easier the activation and hence, the more potent the nucleoside. There's not much difference in the activity between both 3'-dC conformers.

\subsection{Vibrational Spectroscopy}

Table 2 compares simulated vibrational frequencies of I and IIA in vacuum using the B3LYP/6-311++ G**model. In this table, the vibrational frequencies of IIA previouslycalculated using the B3LYP/6-31G* model by (Selvam, Chen, \& Wang, 2010) are also listed.It has been demonstrated that when combined with a moderate basis set such as $6-31 \mathrm{G}^{*}$, the B3LYP functional could provide accurate vibrational frequencies of $2^{2}$-dC with experimental measurement. All wave numbers are scaled by 0.9613 (Selvam, Chen, \& Wang, 2010). The calculated vibrational frequencies of IIA using the same B3LYP functional but larger basis set agree well with those of (Selvam, Chen, \& Wang, 2010). The small discrepancies between the two models may attribute to the different basis set that is used.For example, the C(2')-H stretch mode is given by $2911.38 \mathrm{~cm}^{-1}$ in the present study whereas this stretch vibration is given by $2866.90 \mathrm{~cm}^{-1}$ in (Selvam, Chen, \& Wang, 2010). As a result, this model is applied to calculate the vibrational frequencies.

Figure 3 compares the simulated IR spectra of I and IIA in vacuum. Both IR spectra are concentrated in three regions: $v_{1} \in\left[500-1750 \mathrm{~cm}^{-1}\right], v_{2} \in\left[2850-3150 \mathrm{~cm}^{-1}\right]$ and $v_{3} \in\left[3450-4000 \mathrm{~cm}^{-1}\right]$. The first region $v_{1}[500-1750$ $\left.\mathrm{cm}^{-1}\right]$ consists of a number of spectral peaks in which the most intensive peakis due to the keto $C(2)=O(2)$ stretch vibrations. The $\mathrm{C}(2)=\mathrm{O}(2)$ stretch vibration in $\mathbf{I}$ is given by $1692.86 \mathrm{~cm}^{-1}$, whereas this vibration becomes $1651.33 \mathrm{~cm}^{-1}$ in IIA, corresponding toa red-shift of $41.53 \mathrm{~cm}^{-1}$. The red-shift is caused by a much 
strongerbase-sugar H-bond interaction, $\mathrm{C}(2)=\mathrm{O}(2) \cdots \mathrm{H}-\mathrm{O}\left(2^{\prime}\right)$ with a distance of $2.008 \AA$.

The spectral region $v_{3} \in\left[3450-4000 \mathrm{~cm}^{-1}\right]$ is the "signature" region for I and IIA, which shows the most significant differences between I and IIA. This region above $3300 \mathrm{~cm}^{-1}$ is dominated by the O-H and N-Hstretch vibrations and is associated with H-bonds interactions. The insert spectrum enlarges the IR spectra of Figure 3 in the $3300-4000 \mathrm{~cm}^{-1}$ region, together with the assignment of the individual spectral peaks. As both I and IIA have the same numbers of $-\mathrm{OH}$ groups and $-\mathrm{NH}_{2}$ group, i.e. four spectral peaks with two $\mathrm{O}-\mathrm{H}$ stretches $\left(\mathrm{O}\left(2^{\prime}\right)-\mathrm{H}\right.$ and $\mathrm{O}\left(5^{\prime}(-\mathrm{H})\right)$ and two $-\mathrm{NH}_{2}$ stretches (symmetric and asymmetric). Three out of four vibrations in this region of $\mathbf{I}$ and IIA are almost unchanged, except for the significant changes in both frequency and intensity of the $\mathrm{O}\left(2^{\prime}\right)-\mathrm{H}$ stretch. For example, the $-\mathrm{NH}_{2}$ symmetric stretches in I and IIA are given by $3462.07 \mathrm{~cm}^{-1}$ and $3462.60 \mathrm{~cm}^{-1}$, the $-\mathrm{NH}_{2}$ asymmetric stretches in I and IIA are given by $3590.44 \mathrm{~cm}^{-1}$ and $3589.43 \mathrm{~cm}^{-1}$. The $\mathrm{O}\left(5^{\prime}\right)-\mathrm{H}$ stretch vibration has the highest frequency for both I and IIA and is given by $3670.76 \mathrm{~cm}^{-1}$ and $3683.80 \mathrm{~cm}^{-1}$, respectively. The major difference between $\mathbf{I}$ and IIA is the $\mathrm{O}\left(2^{\prime}\right)-\mathrm{H}$ stretch vibration. In I, the $\mathrm{O}\left(2^{\prime}\right)-\mathrm{H}_{\text {str }}$ vibration at $v=3658.89 \mathrm{~cm}^{-1}$ has the second highest wavenumber spectral peak in this region, whereas in IIA, this vibration significantly shifts to $v=3553.05 \mathrm{~cm}^{-1}$, corresponding to a red-shift of $\Delta v=105.84 \mathrm{~cm}^{-1}$, and is also the most intensive spectral peak in this region in IIA. The middle spectral region of $v_{2} \in\left[2850-3150 \mathrm{~cm}^{-1}\right]$ exclusively involves the $\mathrm{C}-\mathrm{H}$ stretching vibrations. IntramolecularH-bonding of the nucleosides caused blue shift of certain affected C-H bonds, which have been discussed previously (Ahmed \& Wang, 2013).

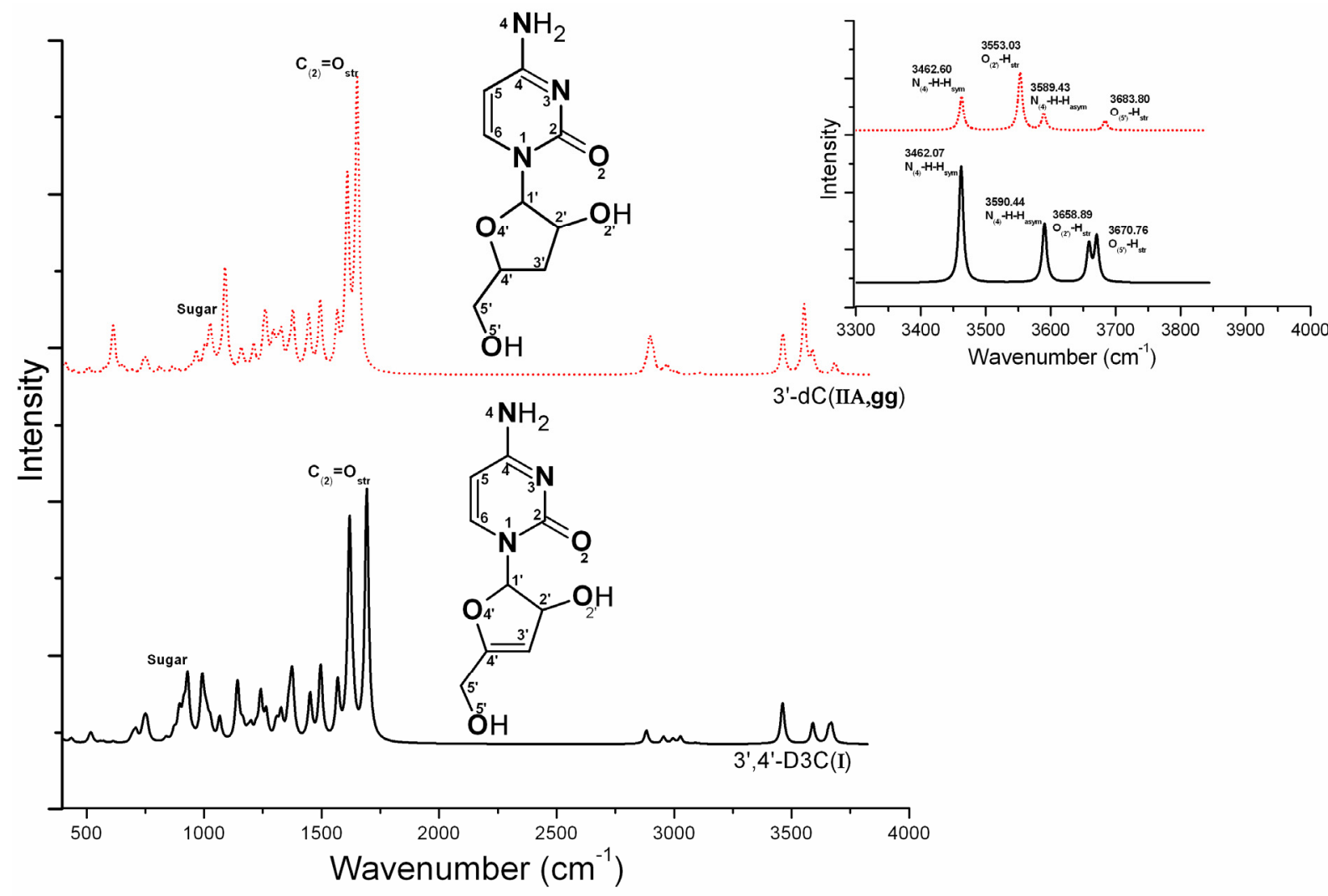

Figure 3. Comparison of thesimulated IR spectra of I (lower panel) and IIA (upper panel) in vacuum. A scale of 0.9613 is applied. Lorentzian broadening shape function with a full width at half maximum (FWHM) of $10 \mathrm{~cm}^{-1}$ and $4 \mathrm{~cm}^{-1}$, respectively, are applied to the main and insert spectra

\subsection{Solvent Effects on the IR Spectra}

Explicit solvent-solute interaction is the most appropriate way to study the solvent-solute interactions and to track the solute property changes upon introduction of solvation (Ganesan et al., 2012). For studying the first hydration shell, for example, explicit water molecules must be included as we will see in the next section (3'-dC solvation shell). The computational cost of the explicit solvent models, however, is often very high. Alternatively, implicit solvent models are a cost effective way to study the solvent effects. This model studies the effects of 
solvent on molecular properties rather than the explicit solvent-solute interactions. Several solvent models, such as the generalized-Born model (GB model), the Poison-Boltzmann model (PB model) (Bashford \& Case, 2000), the conductor like Screening MOdel (COSMO) (Klamt \& Schuurmann, 1993) and the polarisable continuum model (PCM) have been previously described in several studies (Roux \& Simonson, 1999; Feig \& Brooks-Iii, 2004; Mennucci et al., 2002; Tomasi, Mennucci, \& Cammi, 2005). Like most implicit solvent models, the PCM model ignores direct short range solvent-solute explicit interactions, which may be a limitation if the explicit interaction is necessary, namely for solute-solvent complexes exhibiting hydrogen bonds (Alagona \& Ghio, 2006).

Table 2. Comparison of selected simulated IR frequencies and intensities of I and IIA (in vacuum)

\begin{tabular}{|c|c|c|c|c|}
\hline \multicolumn{2}{|l|}{ 3',4'-D3C (I) } & \multicolumn{3}{|c|}{ 3'-dC (IIA) } \\
\hline $\boldsymbol{v}\left(\mathrm{cm}^{-1}\right)$ (intensity $\left.\mathrm{km} \mathrm{mol}^{-1}\right)$ & Assign. & \multicolumn{2}{|c|}{$\boldsymbol{v}\left(\mathrm{cm}^{-1}\right)\left(\right.$ intensity $\left.\mathrm{km} \mathrm{mol}^{-1}\right)$} & Assign. \\
\hline This work ${ }^{\mathrm{a}}$ & & This work $^{\mathrm{a}}$ & Selvam et al. ${ }^{\mathrm{b}, \mathrm{c}}$ & \\
\hline 1634.24 & $v \mathrm{C}_{\left(3^{\prime}\right)}=\mathrm{C}_{\left(4^{\prime}\right)}$ & $1651.33(745.19)$ & & $v \mathrm{C}_{(2)}=\mathrm{O}_{(2)}$ \\
\hline$(647.98)$ & $v \mathrm{C}_{(2)}=\mathrm{O}_{(2)}$ & $2911.38(38.98)$ & 2866.90 & $v \mathrm{C}_{\left(2^{\prime}\right)}-\mathrm{H}_{\mathrm{str}}+v \mathrm{C}_{\left(1^{\prime}\right)}-\mathrm{H}_{\mathrm{str}}$ \\
\hline $2882.09 \quad(34.49)$ & $v \mathrm{C}_{(5},{ }^{\prime}-\mathrm{H}-\mathrm{H}_{\mathrm{sym}}$ & $2880.20(14.08)$ & 2878.70 & $\mathrm{C}_{\left(5^{\prime}\right)}-\mathrm{H}-\mathrm{H}_{\mathrm{sym}}+v \mathrm{C}_{\left(4^{\prime}\right)}-\mathrm{H}_{\mathrm{str}}$ \\
\hline 2954.58 & $v \mathrm{C}_{\left(2^{\prime}\right)}-\mathrm{H}_{\mathrm{str}}$ & $2904.19(9.58)$ & 2970.92 & $v \mathrm{C}_{\left(1^{\prime}\right)}-\mathrm{H}_{\mathrm{str}}+v \mathrm{C}_{\left(2^{\prime}\right)}-\mathrm{H}_{\mathrm{str}}$ \\
\hline 2994.86 & $\left.v \mathrm{C}_{(5}{ }^{\prime}\right)-\mathrm{H}-\mathrm{H}_{\text {asym }}$ & $2895.95(80.96)$ & 2959.56 & $v \mathrm{C}_{\left(4^{\prime}\right)^{\prime}}-\mathrm{H}_{\mathrm{str}}+\mathrm{C}_{\left(5^{\prime}\right)}-\mathrm{H}-\mathrm{H}_{\mathrm{sym}}$ \\
\hline 3026.85 & $v \mathrm{C}_{\left(1^{\prime}\right)}-\mathrm{H}_{\mathrm{str}}$ & $2955.33(8.61)$ & 2964.87 & $v \mathrm{C}_{\left(3^{\prime}\right)}-\mathrm{H}-\mathrm{H}_{\mathrm{sym}}$ \\
\hline 3069.10 & $v \mathrm{C}_{(6)}-\mathrm{H}_{\text {str }}$ & $2970.05(20.46)$ & 2976.36 & $v \mathrm{C}_{\left(5^{\prime}\right)}-\mathrm{H}-\mathrm{H}_{\text {asym }}$ \\
\hline 3090.26 & $v \mathrm{C}_{(5)}-\mathrm{H}_{\mathrm{str}}$ & $3004.58(8.23)$ & 3011.75 & $v \mathrm{C}_{\left(3^{\prime}\right)}-\mathrm{H}-\mathrm{H}_{\text {asym }}$ \\
\hline 3111.52 & $v \mathrm{C}_{\left(3^{\prime}\right)}-\mathrm{H}_{\mathrm{str}}$ & $3085.27(0.71)$ & 3107.91 & $v \mathrm{C}_{(5)}-\mathrm{H}_{\mathrm{str}}$ \\
\hline $3462.07 \quad(105.18)$ & $v \mathrm{~N}_{(4)}-\mathrm{H}-\mathrm{H}_{\mathrm{sym}}$ & $3112.97(4.84)$ & 3145.88 & $v \mathrm{C}_{(6)}-\mathrm{H}_{\mathrm{str}}$ \\
\hline $3590.44 \quad(53.29)$ & $v \mathrm{~N}_{(4)}-\mathrm{H}-\mathrm{H}_{\text {asym }}$ & $3462.60(106.19)$ & 3458.82 & $v \mathrm{~N}_{(4)}-\mathrm{H}-\mathrm{H}_{\mathrm{sym}}$ \\
\hline $3658.89 \quad(32.82)$ & $v \mathrm{O}_{\left(2^{\prime}\right)}-\mathrm{H}_{\text {str }}$ & $3553.03(179.31)$ & 3425.58 & $v \mathrm{O}_{\left(2^{\prime}\right)}-\mathrm{H}_{\text {str }}$ \\
\hline \multirow[t]{2}{*}{$3670.76 \quad(39.76)$} & $v \mathrm{O}_{\left(5^{\prime}\right)}-\mathrm{H}_{\mathrm{str}}$ & $3589.43(52.60)$ & 3577.41 & $v \mathrm{~N}_{(4)}-\mathrm{H}-\mathrm{H}_{\text {asym }}$ \\
\hline & & $3683.80(29.27)$ & 3580.39 & $v \mathrm{O}_{\left(5^{\prime}\right)}-\mathrm{H}_{\mathrm{str}}$ \\
\hline
\end{tabular}

${ }^{\mathrm{a}} \mathrm{B} 3 \mathrm{LYP} / 6-311++\mathrm{G}^{* *}$, scaled by 0.9613 .

${ }^{\mathrm{b}}$ B3LYP/6-31G*, see (Selvam, Chen, \& Wang, 2010).

${ }^{\mathrm{c}}$ L. Selvam, Simulation of spectroscopic properties of atoms and molecules, PhD thesis, Swinburne University of Technology, Australia, 2012.

The red-shifts or blue shifts showed in the IR spectra of I and IIA in solvents could provide useful information to reveal their intramolecular interactions as found by (Selvam, Chen, \& Wang, 2010). That is, the nucleosides in each solvent are optimized again before their IR spectral calculations. Four solvents of various polarities are selected in the study including benzene $(\varepsilon=2.27)$, tetrahydrofuran $(\mathrm{THF}, \varepsilon=7.43)$, tetrahydrothiophene-s,s-dioxide (THT, $\varepsilon=43.96)$ and water $(\varepsilon=78.36)$. Table 3 presents some selected IR spectral shifts of I and IIA in those solvents with respect to the gas phase spectra in the IR region of $v>1500$ $\mathrm{cm}^{-1}$. Solvent causes mostly red-shift I and IIA and the amplitudes of the shifts are proportional to the dielectric constant of the solvents. For I, small red-shift $\left(|\Delta v|<20 \mathrm{~cm}^{-1}\right)$ occurs in the region of $v>3460 \mathrm{~cm}^{-1}$. In the region of $v<1700 \mathrm{~cm}^{-1}$, the red-shift of the $\mathrm{C}=\mathrm{O}$ vibration is the largest in all solvents, . The $\mathrm{C}(3)=\mathrm{C}(4)$ double bond exhibits a shift switching from red shift in non(low)-polar solvents to blue shift in polar solvents: the $\mathrm{C}=\mathrm{C}$ stretch vibration slightly red shifts $(\Delta v<0)$ in non-polar solvents such as benzene but switches sign in polar solvent such as water $(\Delta v>0)$. The $-\mathrm{NH}_{2}$ asymmetric band at $3590.44 \mathrm{~cm}^{-1}$ red shifts $-4 \mathrm{~cm}^{-1}$ in benzene $(\varepsilon=2.27),-10.29$ $\mathrm{cm}^{-1}$ in THF $(\varepsilon=7.43),-13.91 \mathrm{~cm}^{-1}$ in THT $(\varepsilon=43.96)$ and $-14.32 \mathrm{~cm}^{-1}$ in water $(\varepsilon=78.36)$. The largest red-shift is the $\mathrm{C}=\mathrm{O}$ stretch vibration at $1692.86 \mathrm{~cm}^{-1}$, which red shifts $-36.37 \mathrm{~cm}^{-1},-68.51 \mathrm{~cm}^{-1},-82.21 \mathrm{~cm}^{-1}$, and -83.28 $\mathrm{cm}^{-1}$ in benzene, THF, THT and water solvents, respectively.

As shown in Table 3, the $\mathrm{C}=\mathrm{O}$ stretch vibration of IIA exhibits the largest red-shift in solvent and the shift increases as the dielectric constant becomes larger, the shift is given by $-27 \mathrm{~cm}^{-1},-60 \mathrm{~cm}^{-1},-66.43 \mathrm{~cm}^{-1}$ and $-67.00 \mathrm{~cm}^{-1}$ in benzene, THF, THT and water solvents, respectively, with respect to their gas phase vibration.

Figure $4(\mathrm{a}, \mathrm{b})$ illustrates the significant IR spectral shift associate with the $\mathrm{C}(2)=\mathrm{O}(2), \mathrm{O}\left(2^{\prime}\right)=\mathrm{H}$ and $\mathrm{O}\left(5^{\prime}\right)-\mathrm{H}$ in I and IIA, respectively. Significant red shift of the $\mathrm{C}=\mathrm{O}$ vibration is seen in both nucleosides, which is enhanced by polar solvents. The trends somehow obeys an exponential relation as discussed earlier by (Selvam, Chen, \& 
Wang, 2010).

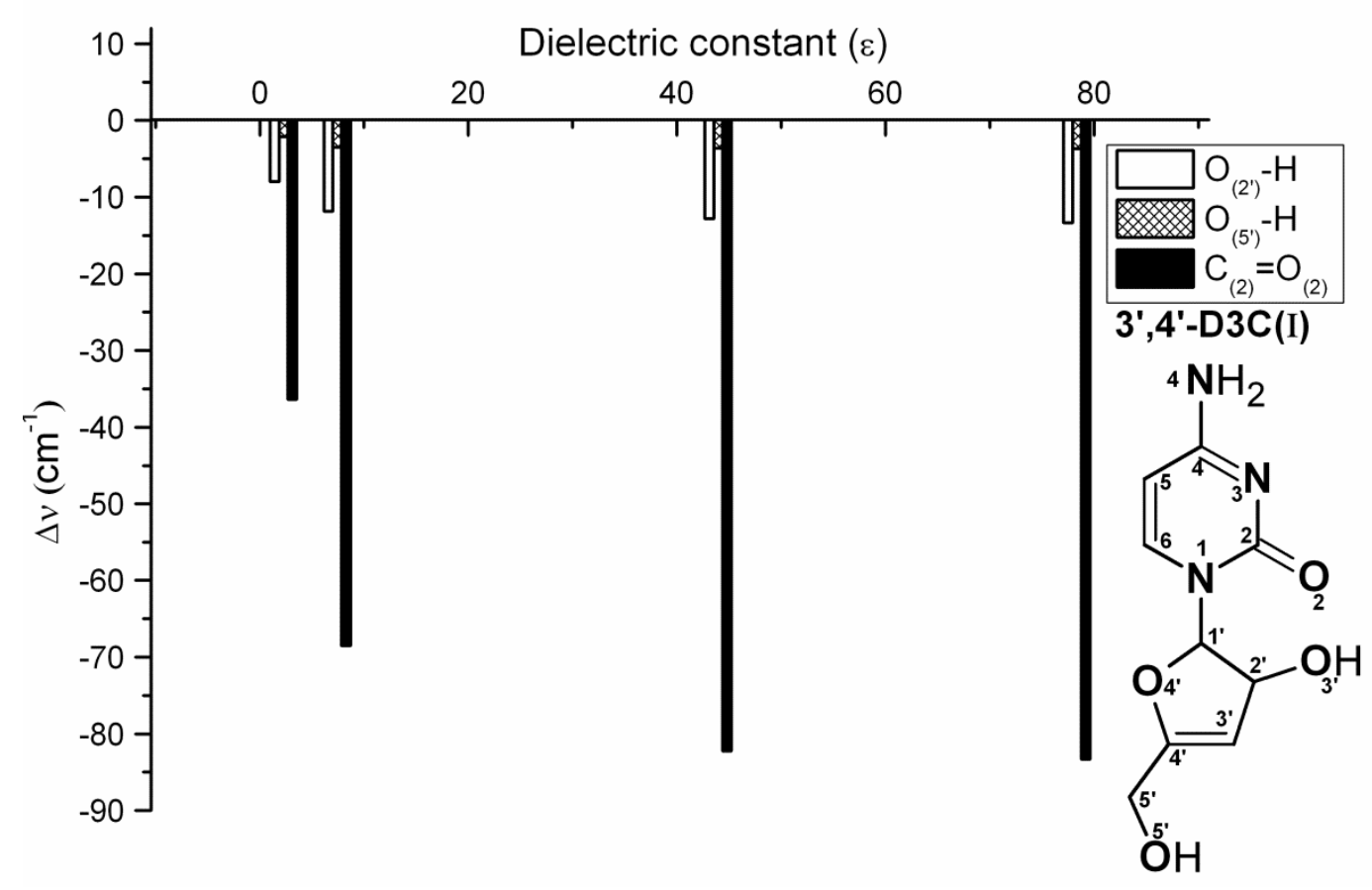

(a)

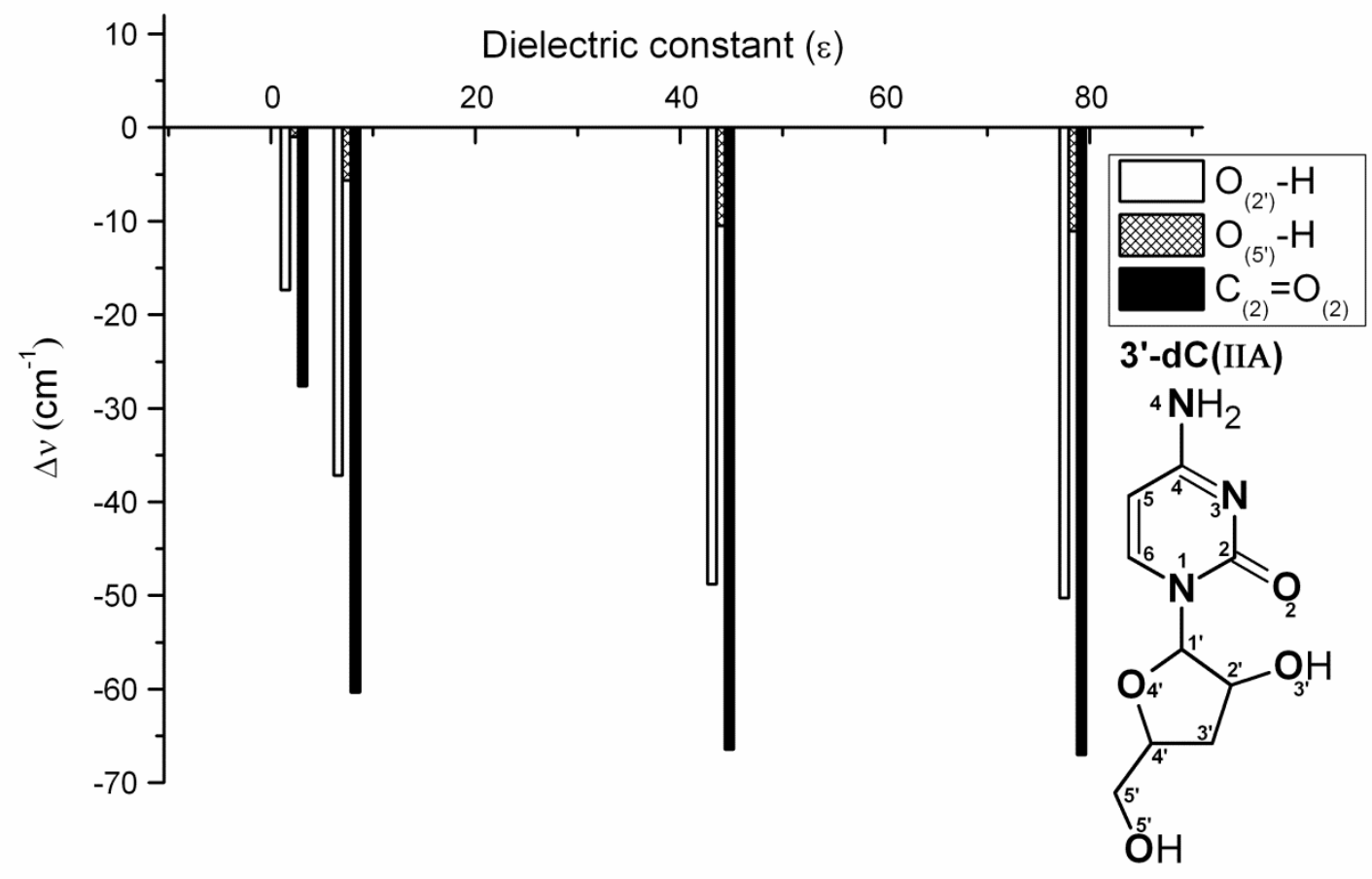

(b)

Figure 4. Significant IR spectral shifts (a) for I and (b) for IIA in the local region of C( $\left.3^{\prime}\right)-C\left(4^{\prime}\right)$ and $C=O$ intramolecular interactions in various solvents, benzene $(\varepsilon=2.27$ ), tetrahydrofuran (THF, $\varepsilon=7.43$ ), tetrahydrothiophene-s,s-dioxide (THT, $\varepsilon=43.96)$ and water $(\varepsilon=78.36)$ 
Table 3. IR spectral frequency shifts I and IIA in various solvents with respect to vacuum ${ }^{\mathrm{a}}$

\begin{tabular}{|c|c|c|c|c|c|}
\hline \multicolumn{6}{|c|}{ 3',4'-D3C (I) } \\
\hline Vacuum & $\begin{array}{l}\Delta v(\text { Ben })^{\mathrm{b}} \\
(\varepsilon=2.27)\end{array}$ & $\begin{array}{l}\Delta v{\text { (THF })^{\mathrm{b}}}^{(\varepsilon=7.43)} \\
\end{array}$ & $\begin{array}{l}\Delta v(\mathrm{THT})^{\mathrm{b}} \\
(\varepsilon=43.96)\end{array}$ & $\begin{array}{l}\Delta v{\text { ( Water })^{b}}^{b} \\
(\varepsilon=78.36)\end{array}$ & Assignment \\
\hline 1634.24 & -0.51 & -0.10 & 0.64 & 0.75 & $v \mathrm{C}_{\left(3^{\prime}\right)}=\mathrm{C}_{\left(4^{\prime}\right)}$ \\
\hline 1692.86 & -36.37 & -68.51 & -82.21 & -83.28 & $v \mathrm{C}_{(2)}=\mathrm{O}_{(2)}$ \\
\hline 3462.07 & -1.58 & -5.06 & -7.21 & -7.44 & $v \mathrm{~N}_{(4)}-\mathrm{H}-\mathrm{H}_{\mathrm{sym}}$ \\
\hline 3590.44 & -4.00 & -10.29 & -13.91 & -14.32 & $v \mathrm{~N}_{(4)}-\mathrm{H}-\mathrm{H}_{\text {asym }}$ \\
\hline 3658.89 & -7.98 & -11.83 & -12.79 & -13.32 & $v \mathrm{O}_{\left(2^{2}\right)}-\mathrm{H}_{\mathrm{str}}$ \\
\hline 3670.76 & -2.13 & -3.48 & -3.61 & -3.68 & $\left.v \mathrm{O}_{\left(5^{\prime}\right)}\right)^{-\mathrm{H}_{\text {str }}}$ \\
\hline \multicolumn{6}{|c|}{ 3'-dC (II) } \\
\hline Vacuum & $\begin{array}{l}\Delta v(\text { Ben })^{\mathrm{b}} \\
(\varepsilon=2.27)\end{array}$ & $\begin{array}{l}\Delta \boldsymbol{v}(\mathrm{THF})^{\mathrm{b}} \\
(\varepsilon=7.43)\end{array}$ & $\begin{array}{l}\Delta \boldsymbol{v}(\mathrm{THT})^{\mathrm{b}} \\
(\varepsilon=43.96)\end{array}$ & $\begin{array}{l}\Delta \boldsymbol{v}(\text { Water })^{\mathrm{b}} \\
(\varepsilon=78.36)\end{array}$ & Assignment \\
\hline 1651.33 & -27.63 & -60.35 & -66.43 & -67.00 & $v \mathrm{C}_{(2)}=\mathrm{O}_{(2)}$ \\
\hline 3462.60 & 1.12 & -2.51 & -4.63 & -4.84 & $v \mathrm{~N}_{(4)}-\mathrm{H}-\mathrm{H}_{\mathrm{sym}}$ \\
\hline 3553.03 & -17.34 & -37.19 & -48.78 & -50.27 & $v \mathrm{O}_{\left(2^{\prime}\right)}-\mathrm{H}_{\text {str }}$ \\
\hline 3589.43 & 0.05 & -6.58 & -10.27 & -10.6 & $v \mathrm{~N}_{(4)}-\mathrm{H}-\mathrm{H}_{\mathrm{asym}}$ \\
\hline 3683.80 & -0.99 & -5.65 & -10.49 & -11.07 & $\left.v \mathrm{O}_{\left(5^{\prime}\right)}\right)^{-\mathrm{H}_{\text {str }}}$ \\
\hline
\end{tabular}

${ }^{a}$ Based on the B3LYP/6-311++G** level of theory and applying the PCM model for solvent effect, scaled by 0.9613, $\Delta v$ values are coloured according to the type of shift, red for red shifts and blue for blue shifts.

${ }^{\mathrm{b}} \Delta \boldsymbol{v}\left(\mathrm{cm}^{-1}\right)=\boldsymbol{v}_{\text {solvent }}-\boldsymbol{v}_{\text {vacuum. }}$.

\subsection{3'-Dc Solvation Shell}

Figure 5(a1) represents the final trajectory snapshot of 3'-dC together with the nearest 10 water molecules. We have also included a confirmation that is similar to the gas phase/implicit solvent globally optimized conformation in Figure 5(a2). Figure 5b displays the radial pair distribution functions (RDFs) between this atom $\left(\mathrm{O}_{2}\right)$ and any water hydrogen (HW) within the first hydration shell. The figure also includes the RDF data between $\left(\mathrm{O}_{5}, \mathrm{H}_{5}\right.$, and any water oxygen $(\mathrm{OW})$ within the first hydration shell. From a geometrical point of view, it could have been very convenient to turn on a pure QM Hamiltonian, but, this is very challenging for several reasons. First; the computational expense associated with such treatment is very high limiting the simulation to the ps time scale. Second; for such simulations at this short time scale, it's very unlikely to effectively sample the conformational space and more complex sampling techniques such as Replica Exchange Molecular Dynamics (REMD) may also be necessary (Rosta \& Hummer, 2009; García \& Sanbonmatsu, 2002; Sugita \& Okamoto, 1999). Research in this direction is currently in progress.

As shown in Figure 5(a,b), the $\mathrm{O}_{2}$ atom is tetra-coordinated directly with four water molecules by the aid of four intramolecular H-bonds. This is also explained by the very strong peak at $1.45 \AA$ (attributed to $\mathrm{O}_{2} \cdots \mathrm{HW}_{1}$ and $\mathrm{O}_{2} \cdots \mathrm{HW}_{2}$ ) as shown in the RDF figure (Figure 5b). For $\mathrm{H}_{5}, \cdots \mathrm{OW}$, the RDF plot shows a much lower (almost 1/4) peak at around $1.75 \AA$ indicating mono-coordination.

\section{Conclusions}

The present study reveals how the properties and vibrational spectra of the cytidine nucleoside derivative, 3',4'-didehydro-3'-deoxycytidine (I) from those of 3'-deoxycytidine (II), as the saturation of the C(3') $=\mathrm{C}\left(4^{\prime}\right)$ bond in the sugar ring. The study also identified the presence of two low energy conformers and linked to the two experimentally resolved conformations, IIA and IIB. Such structural alternation impacts on their intramolecular H-bonding network, such as $\mathrm{O}\left(2^{\prime}\right)-\mathrm{H} \cdots \mathrm{O}(2)=\mathrm{C}(2)$, which has been indicated by their IR spectral shifts. It is found that the double bond leads to hydrogen bond related IR spectral red-shifted in solvents. The polarisable continuum model (PCM) confirms our previous founding that the amplitudes of the red-shifts increase as the solvent dielectric constants(Selvam, Chen, \& Wang, 2010).Studying the first hydration shell reveals that water molecules have higher preference for the carbonyl oxygen which is tetra-coordinated with four 
water molecules. The present study further indicates using the Fukui function that the double bond can be used to activate or deactivate sugar carbon sites by chemical modification, which provides useful information for drug design.

(a1)
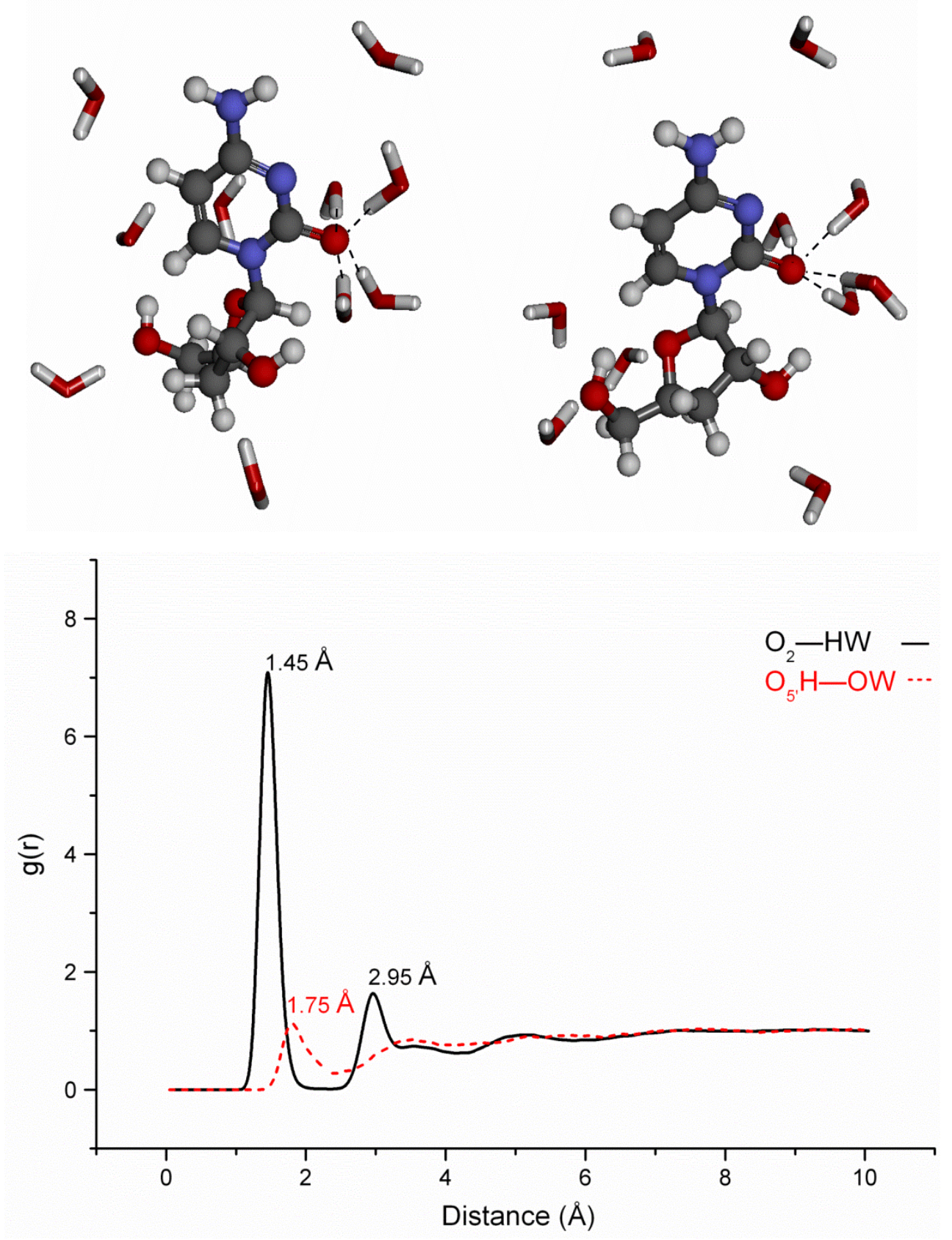

(b)

(a2)

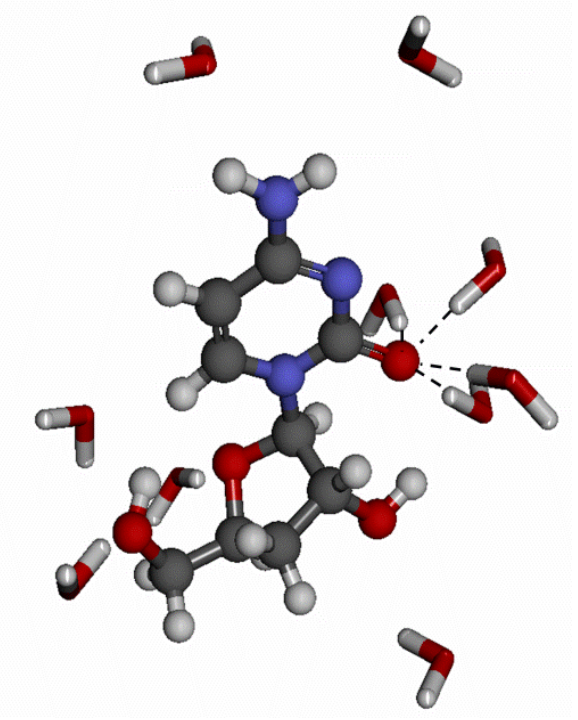

$$
\begin{aligned}
& \mathrm{O}_{2}-\mathrm{HW}- \\
& \mathrm{O}_{5} \mathrm{H}-\mathrm{OW} \cdots
\end{aligned}
$$

Distance $(\AA)$

Figure 5. (a1) First hydration shell of the final QM/MM MD trajectory snapshot of 3'-dC, (a2) first hydration shell of an intermediate QM/MM MD trajectory snapshot of 3'-dC that is similar to the optimized gas phase/implicit solvent conformation, potential solute-solvent H-bonds are shown in dashed lines and (b) RDF plots for between two 3'-dC atomic sites and the corresponding solvent atoms; the $\mathrm{O}_{2} \cdots \mathrm{HW}$ and the

$$
\mathrm{O}\left(5^{\prime}\right) \mathrm{H} \cdots \mathrm{OW}
$$




\section{Acknowledgements}

MA acknowledges the Swinburne University Postgraduate Research Award (SUPRA). National Computational Infrastructure (NCI) at the Australian National University for the award under the Merit Allocation Scheme (MAS), Victorian Partnership for Advanced Computing (VPAC) and Swinburne University Supercomputing Facilities Green/gSTAR machines are acknowledged.

\section{References}

Ahmed, M., \& Wang, F. (2013). Vibrational spectroscopy and intramolecular hydrogen bond network of (didehydro) deoxycytidine nucleosides. Curr. Phys. Chem. Manuscript submitted for publication.

Alagona, G., \& Ghio, C. (2006). Protonated serotonin conformational landscape in vacuo and in aqueous solution (IEF-PCM): Role of correlation effects and monohydration. J. Mol. Struct. (THEOCHEM), 769(1-3), 123-134. http://dx.doi.org/10.1016/j.theochem.2005.12.039

Alcolea-Palafox, M., \& Iza, N. (2012). Structure of the antiviral stavudine using quantum chemical methods: Complete conformational space analysis, 3D potential energy surfaces and solid state simulations. Journal of Molecular Structure, 1028, 181-195. http://dx.doi.org/10.1016/j.molstruc.2012.06.022

Altona, C., \& Sundaralingam, M. (1972). Conformational analysis of the sugar ring in nucleosides and nucleotides. New description using the concept of pseudorotation. J. Am. Chem. Soc., 94(23), 8205-8212. http://dx.doi.org/10.1021/ja00778a043

Arnott, S., \& Hukins, D. W. L. (1969). Conservation of Conformation in Mono and Poly-nucleotides. Nature, 224(5222), 886-888. http://dx.doi.org/10.1038/224886a0

Bashford, D., \& Case, D. A. (2000). Generalized Born Models of Macromolecular Solvation Effects. Annu. Rev. Phys. Chem., 51(1), 129-152. http://dx.doi.org/10.1146/annurev.physchem.51.1.129

Bell, A. F., Hecht, L., \& D. Barron, L. (1997). Vibrational Raman optical activity of pyrimidine nucleosides. J. Chem. Soc., Faraday Trans., 93(4), 553-562. http://dx.doi.org/10.1039/A606531G

Brooks, R. F. (1978). 3'-Deoxycytidine, like hydroxyurea, inhibits DNA synthesis without preventing the initiation of the cell cycle. Cell Biol. Int., 2(3), 279-291. http://dx.doi.org/10.1016/0309-1651(78)90008-5

Case, D. A., Cheatham, T. E., Darden, T., Gohlke, H., Luo, R., Merz, K. M., ... Woods, R. J. (2005). The Amber biomolecular simulation programs. J. Comput. Chem., 26(16), 1668-1688. http://dx.doi.org/10.1002/jcc.20290

Chen, F., \& Wang, F. (2009). Electronic structure of the azide group in 3-Azido-3- deoxythymidine (AZT) compared to small azide compounds. Molecules, 14(7), 2656-2668. http://dx.doi.org/10.3390/molecules 14072656

Chen, F., Selvam, L., \& Wang, F. (2010). Blue shifted intramolecular C-H $\cdots \mathrm{O}$ improper hydrogen bonds in conformers of zidovudine. Chem. Phys. Lett., 493(4-6), 358-363. http://dx.doi.org/10.1016/j.cplett.2010.05.057

Chidangil, S., \& Mishra, P. C. (1997). Structure-Activity Relationship for Some 2',3'-Dideoxynucleoside Anti-HIV Drugs Using Molecular Electrostatic Potential Mapping. J. Mol. Model., 3(4), 172-181. http://dx.doi.org/10.1007/s008940050029

Choi, Y., George, C., Comin, M. J., Barchi, J. J., Kim, H. S., Jacobson, K. A., ... Marquez, V. E. (2003). A Conformationally Locked Analogue of the Anti-HIV Agent Stavudine. An Important Correlation between Pseudorotation and Maximum Amplitude. J. Med. Chem., 46(15), 3292-3299. http://dx.doi.org/10.1021/jm030116g

Chong, D. P., Van Lenthe, E., Van Gisbergen, S., \& Baerends, E. J. (2004). Even-tempered slater-type orbitals revisited: From hydrogen to krypton. J. Comput. Chem., 25(8), 1030-1036. http://dx.doi.org/10.1002/jcc.20030

Clercq, E. D. (2004). Antivirals and antiviral strategies. Nat. Rev. Micro., 2(9), 704-720. http://dx.doi.org/10.1038/nrmicro975

Cossi, M., Rega, N., Scalmani, G., \& Barone, V. (2003). Energies, structures, and electronic properties of molecules in solution with the C-PCM solvation model. J. Comput. Chem., 24(6), 669-681. http://dx.doi.org/10.1002/jcc.10189

Darden, T., York, D., \& Pedersen, L. (1993). Particle mesh Ewald: An N.log(N) method for Ewald sums in large 
systems. J. Chem. Phys., 98(12), 10089-10092. http://dx.doi.org/10.1063/1.464397

Davidson, E. R., \& Chakravorty, S. (1992). A test of the Hirshfeld definition of atomic charges and moments. Theor. Chem. Accounts. Theor. Comput. Model. Theor. Chim. Acta, 83(5), 319-330. http://dx.doi.org/10.1007/BF01113058

Dolgonos, G., Aradi, B., Moreira, N. H., \& Frauenheim, T. (2009). An Improved Self-Consistent-Charge Density-Functional Tight-Binding (SCC-DFTB) Set of Parameters for Simulation of Bulk and Molecular Systems Involving Titanium. J. Chem. Theor. Comput., 6(1), 266-278. http://dx.doi.org/10.1021/ct900422c

Duffy, P. (2008). Valence orbital response to pseudorotation of tetrahydrofuran: A snapshot using dual space analysis. J. Chem. Phys., 128(12), 125102-125112. http://dx.doi.org/10.1063/1.2838852

Elstner, M., Hobza, P., Frauenheim, T., Suhai, S., \& Kaxiras, E. (2001). Hydrogen bonding and stacking interactions of nucleic acid base pairs: A density-functional-theory based treatment. J. Chem. Phys., 114(12), 5149-5155. http://dx.doi.org/10.1063/1.1329889

Feig, M., \& Brooks Iii, C. L. (2004). Recent advances in the development and application of implicit solvent models in biomolecule simulations. Curr. Opin. Struct. Biol., 14(2), 217-224. http://dx.doi.org/10.1016/j.sbi.2004.03.009

Fernández-Calotti, P. X., Colomer, D., \& Pastor-Anglada, M. (2011). Translocation of Nucleoside Analogs Across the Plasma Membrane in Hematologic Malignancies. Nucleos. Nucleot. Nucl., 30(12), 1324-1340. http://dx.doi.org/10.1080/15257770.2011.597372

Frisch, M. J., Trucks, G. W., Schlegel, H. B., Scuseria, G. E., Robb, M. A. Cheeseman, J. R., ... Pople, J. A. (2009). Gaussian 09, Revision A.02, Gaussian, Inc., Wallingford, CT.

Fukui, K. (1982). Role of Frontier Orbitals in Chemical Reactions. Science, 218(4574), 747-754. http://dx.doi.org/10.1126/science.218.4574.747

Galmarini, C. M., Jordheim, L., \& Dumontet, C. (2003). Pyrimidine nucleoside analogs in cancer treatment. Expet. Rev. Anticancer. Ther., 3(5), 717-728. http://dx.doi.org/10.1586/14737140.3.5.717

Galmarini, C. M., Mackey, J. R., \& Dumontet, C. (2001). Nucleoside analogues: mechanisms of drug resistance and reversal strategies. Leukemia, 15(6), 875-890. Retrieved from http://pubget.com/paper/11417472http://www.nature.com/leu/journal/v15/n6/pdf/2402114a.pdf

Galmarini, C. M., Mackey, J. R., \& Dumontet, C. (2002). Nucleoside analogues and nucleobases in cancer treatment. Lancet Oncol., 3(7), 415-424. http://dx.doi.org/10.1016/s1470-2045(02)00788-x

Ganesan, A., Dreyer, J., Larrucea, J., Wang, F., \& Akola, J. (2012). CPMD simulation of $\mathrm{Cu}+2$ - phenylalanine complex under micro-solvated environment. Manuscript submitted for publication.

García, A. E., \& Sanbonmatsu, K. Y. (2002). $\alpha$-Helical stabilization by side chain shielding of backbone hydrogen bonds. Proc. Natl. Acad. Sci. Unit. States Am., 99(5), 2782-2787. http://dx.doi.org/10.1073/pnas.042496899

Gaus, M., Cui, Q., \& Elstner, M. (2011). DFTB3: Extension of the Self-Consistent-Charge Density-Functional Tight-Binding Method (SCC-DFTB). J. Chem. Theor. Comput., 7(4), 931-948. http://dx.doi.org/10.1021/ct100684s

Harte Jr., W. E., Starrett Jr., J. E., Martin, J. C., \& Mansuri, M. M. (1991). Structural studies of the anti-HIV agent 2',3'-didehydro-2',3'-dideoxythymidine (D4T). Biochem. Biophys. Res. Comm., 175(1), 298-304. http://dx.doi.org/10.1016/S0006-291X(05)81234-3

Huang, Z., Yu, W., \& Lin, Z. (2006). Exploration of the full conformational landscapes of gaseous aromatic amino acid phenylalanine: An ab initio study. J. Mol. Struct. (THEOCHEM), 758(2-3), 195-202. http://dx.doi.org/10.1016/j.theochem.2005.10.043

Kaminski, S., Giese, T. J., Gaus, M., York, D. M., \& Elstner, M. (2012). Extended Polarization in Third-Order SCC-DFTB from Chemical-Potential Equalization. J. Phys. Chem. A, 116(36), 9131-9141. http://dx.doi.org/10.1021/jp306239c

Karthe, P., Gautham, N., Kumar, A., \& Katti, S. B. (1997). The Three-Dimensional Structure of 3'-Deoxycytidine. Nucleosides and Nucleotides, 16(1-2), 1-10. http://dx.doi.org/10.1080/07328319708002516

Kilpatrick, J. E., Pitzer, K. S., \& Spitzer, R. (1947). The Thermodynamics and Molecular Structure of Cyclopentane1. J. Am. Chem. Soc., 69(10), 2483-2488. http://dx.doi.org/10.1021/ja01202a069 
Klamt, A., \& Schuurmann, G. (1993). COSMO: a new approach to dielectric screening in solvents with explicit expressions for the screening energy and its gradient. J. Chem. Soc., Perkin Trans. 2, (5), 799-805. http://dx.doi.org/10.1039/P29930000799

Kolandaivel, P., Praveena, G., \& Selvarengan, P. (2005). Study of atomic and condensed atomic indices for reactive sites of molecules. J. Chem. Sci., 117(5), 591-598. http://dx.doi.org/10.1007/BF02708366

Kubar̆, T., Jurečka, P., Černý, J., Řezáč, J., Otyepka, M., Valdés, H., \& Hobza, P. (2007). Density-Functional, Density-Functional Tight-Binding, and Wave Function Calculations on Biomolecular Systems. J. Phys. Chem. A, 111(26), 5642-5647. http://dx.doi.org/10.1021/jp068858j

Lindorff-Larsen, K., Piana, S., Palmo, K., Maragakis, P., Klepeis, J. L., Dror, R. O., \& Shaw, D. E. (2010). Improved side chain torsion potentials for the Amber ff99SB protein force field. Proteins Struct. Funct. Bioinf., 78(8), 1950-1958. http://dx.doi.org/10.1002/prot.22711

Mennucci, B., Tomasi, J., Cammi, R., Cheeseman, J. R., Frisch, M. J., Devlin, F. J., ... Stephens, P. J. (2002). Polarizable Continuum Model (PCM) Calculations of Solvent Effects on Optical Rotations of Chiral Molecules. J. Phys. Chem. A, 106(25), 6102-6113. http://dx.doi.org/10.1021/jp020124t

Ning, C. G., Huang, Y. R., Zhang, S. F., Deng, J. K., Liu, K., Luo, Z. H., \& Wang, F. (2008). Experimental and Theoretical Electron Momentum Spectroscopic Study of the Valence Electronic Structure of Tetrahydrofuran under Pseudorotation. J. Phys. Chem. A, 112(44), 11078-11087. http://dx.doi.org/10.1021/jp8038658

Niwas, S., Chand, P., Pathak, V. P., \& Montgomery, J. A. (1994). Structure-Based Design of Inhibitors of Purine Nucleoside Phosphorylase. 5. 9-Deazahypoxanthines. J. Med. Chem., 37(15), 2477-2480. http://dx.doi.org/10.1021/jm00041a027

Parr, R. G., \& Yang, W. (1984). Density functional approach to the frontier-electron theory of chemical reactivity. J. Am. Chem. Soc., 106(14), 4049-4050. http://dx.doi.org/10.1021/ja00326a036

Rodriguez, J. B., Marquez, V. E., Nicklaus, M. C., Mitsuya, H., \& Barchi, J. J. (1994). Conformationally Locked Nucleoside Analogs. Synthesis of Dideoxycarbocyclic Nucleoside Analogs Structurally Related to Neplanocin C. J. Med. Chem., 37(20), 3389-3399. http://dx.doi.org/10.1021/jm00046a024

Rosta, E., \& Hummer, G. (2009). Error and efficiency of replica exchange molecular dynamics simulations. $J$. Chem. Phys., 131(16), 165102-165112. http://dx.doi.org/10.1063/1.3249608

Roux, B., \& Simonson, T. (1999). Implicit solvent models. Biophys. Chem., 78(1-2), 1-20. http://dx.doi.org/10.1016/s0301-4622(98)00226-9

Salomon-Ferrer, R., Case, D. A., \& Walker, R. C. (2012). An overview of the Amber biomolecular simulation package. WIREs. Comput. Mol. Sci., 3(2), 198-210. http://dx.doi.org/10.1002/wcms.1121

Schinazi, R. F., Mellors, J., Bazmi, H., Diamond, S., Garber, S., Gallagher, K., ... Erickson-Viitanen, S. (2002). DPC 817: a Cytidine Nucleoside Analog with Activity against Zidovudine- and Lamivudine-Resistant Viral $\begin{array}{llll}\text { Variants. Antimicrob. Agents } & \text { 1394-1401. }\end{array}$ http://dx.doi.org/10.1128/aac.46.5.1394-1401.2002

Selvam, L., Chen, F., \& Wang, F. (2010). Solvent effects on blue shifted improper hydrogen bond of C-H...O in deoxycytidine isomers. Chem. Phys. Lett., 500(4-6), 327-333. http://dx.doi.org/10.1016/j.cplett.2010.10.033

Selvam, L., Vasilyev, V., \& Wang, F. (2009). Methylation of Zebularine: A Quantum Mechanical Study Incorporating Interactive 3D pdf Graphs. J. Phys. Chem. B, 113(33), 11496-11504. http://dx.doi.org/10.1021/jp901678g

Sugita, Y., \& Okamoto, Y. (1999). Replica-exchange molecular dynamics method for protein folding. Chem. Phys. Lett., 314(1-2), 141-151. http://dx.doi.org/10.1016/S0009-2614(99)01123-9

Sun, G., Voigt, J. H., Filippov, I. V., Marquez, V. E., \& Nicklaus, M. C. (2004). PROSIT: Pseudo-Rotational Online Service and Interactive Tool, Applied to a Conformational Survey of Nucleosides and Nucleotides. $J$. $\begin{array}{lllll}\text { Chem. Inform. } & \text { Comput. } & \text { Sci., } & \text { 44(5), } & \text { 1752-1762. }\end{array}$ http://dx.doi.org/10.1021/ci049881+http://pubs.acs.org/doi/pdfplus/10.1021/ci049881\%2B

Sundaralingam, M. (1975). Structure and conformation of nucleosides and nucleotides and their analogs as determined by x-ray diffraction. Ann. N.Y. Acad. Sci., 255(1), 3-42. http://dx.doi.org/10.1111/j.1749-6632.1975.tb29211.x 
Te Velde, G., Bickelhaupt, F. M., Baerends, E. J., Fonseca Guerra, C., van Gisbergen, S. J. A., Snijders, J. G., \& Ziegler, T. (2001). Chemistry with ADF. J. Comput. Chem., 22(9), 931-967. http://dx.doi.org/10.1002/jcc.1056

Thompson, A., Saha, S., Wang, F., Tsuchimochi, T., Nakata, A., Imamura, Y., \& Nakai, H. (2009). Density Functional Study on Core Ionization Spectra of Cytidine and Its Fragments. Bull. Chem. Soc. Jpn., 82(2), 187-195. http://dx.doi.org/10.1246/bcsj.82.187

Tomasi, J., Mennucci, B., \& Cammi, R. (2005). Quantum Mechanical Continuum Solvation Models. Chem. Rev., 105(8), 2999-3094. http://dx.doi.org/10.1021/cr9904009

Torrance, C. J., Agrawal, V., Vogelstein, B., \& Kinzler, K. W. (2001). Use of isogenic human cancer cells for high-throughput screening and drug discovery. Nat. Biotech., 19(10), 940-945. http://dx.doi.org/10.1038/nbt1001-940

Van de Streek, J. (2006). Searching the Cambridge Structural Database for the "best" representative of each unique polymorph. Acta Crystallogr. B, 62(4), 567-579. http://dx.doi.org/10.1107/S0108768106019677

Van Leeuwen, R., \& Baerends, E. J. (1994). Exchange-correlation potential with correct asymptotic behavior. Phys. Rev. A, 49(4), 2421-2431. http://dx.doi.org/10.1103/PhysRevA.49.2421

Wang, F. (2007). Unsaturated Didehydrodeoxycytidine Drugs. 1. Impact of CC Positions in the Sugar Ring. J. Phys. Chem. B, 111(32), 9628-9633. http://dx.doi.org/10.1021/jp072014y

Wang, G. (2000). Conformationally locked nucleosides. Synthesis of 3(R,S)-(adenin-9-yl)-1- and 3(R,S)-(cytosin-1-yl)-1-hydroxymethylbicyclo[2,1,1]hexanes. Tetrahedron Lett., 41(37), 7139-7143. http://dx.doi.org/10.1016/s0040-4039(00)01246-6

Wu, Y., Tepper, H. L., \& Voth, G. A. (2006). Flexible simple point-charge water model with improved liquid-state properties. J. Chem. Phys., 124, 024503. http://dx.doi.org/10.1063/1.2136877

Yang, T., Su, G., Ning, C., Deng, J., Wang, F., Zhang, S., ... Huang, Y. (2007). New Diagnostic of the Most Populated Conformer of Tetrahydrofuran in the Gas Phase. J. Phys. Chem. A, 111(23), 4927-4933. http://dx.doi.org/10.1021/jp066299a

Yang, W., \& Mortier, W. J. (1986). The use of global and local molecular parameters for the analysis of the gas-phase basicity of amines. J. Am. Chem. Soc., 108(19), 5708-5711. http://dx.doi.org/10.1021/ja00279a008

Yang, Y., Yu, H., York, D., Elstner, M., \& Cui, Q. (2008). Description of Phosphate Hydrolysis Reactions with the Self-Consistent-Charge Density-Functional-Tight-Binding (SCC-DFTB) Theory. 1. Parameterization. $J$. Chem. Theor. Comput., 4(12), 2067-2084. http://dx.doi.org/10.1021/ct800330d

Yang, Yu, H., York, D., Cui, Q., \& Elstner, M. (2007). Extension of the Self-Consistent-Charge Density-Functional Tight-Binding Method: Third-Order Expansion of the Density Functional Theory Total Energy and Introduction of a Modified Effective Coulomb Interaction. J. Phys. Chem. A, 111(42), 10861-10873. http://dx.doi.org/10.1021/jp074167r

Zhu, Q., Wang, F., \& Ivanova, E. P. (2009). Impact of ketone and amino on the inner shell of guanine. $J$. Synchrotron Radiat., 16(4), 545-552. http://dx.doi.org/10.1107/S0909049509017063 


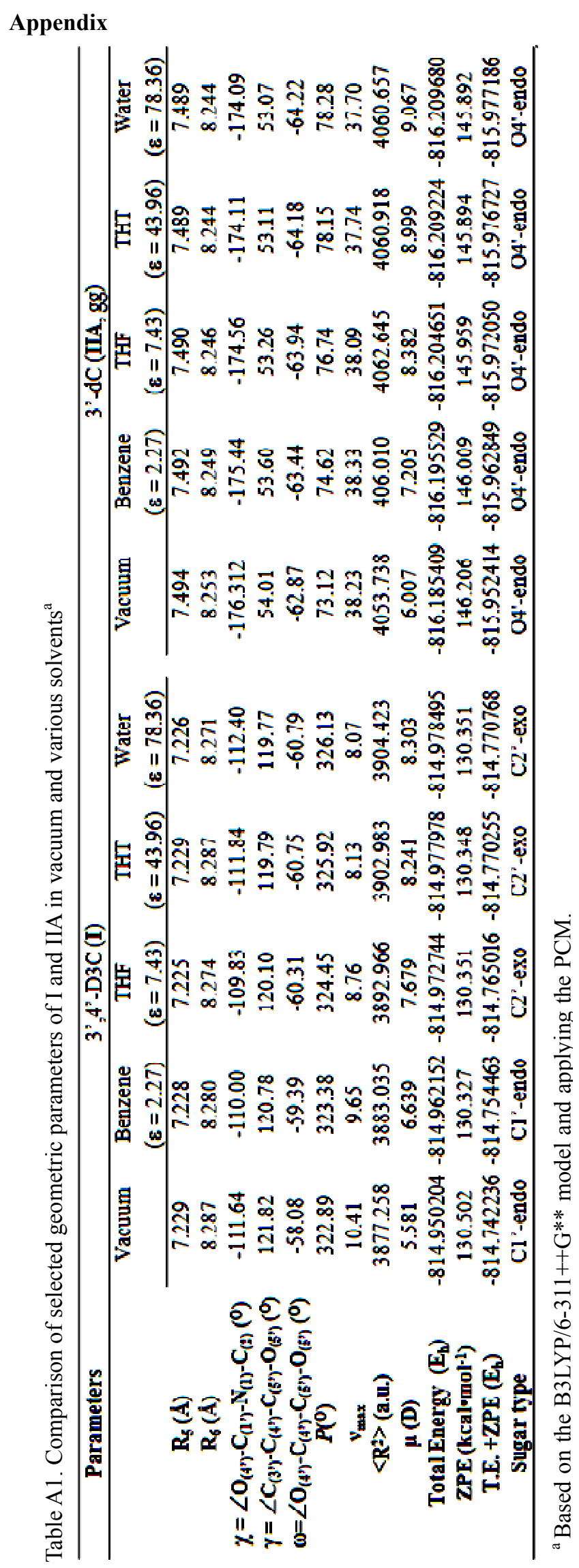




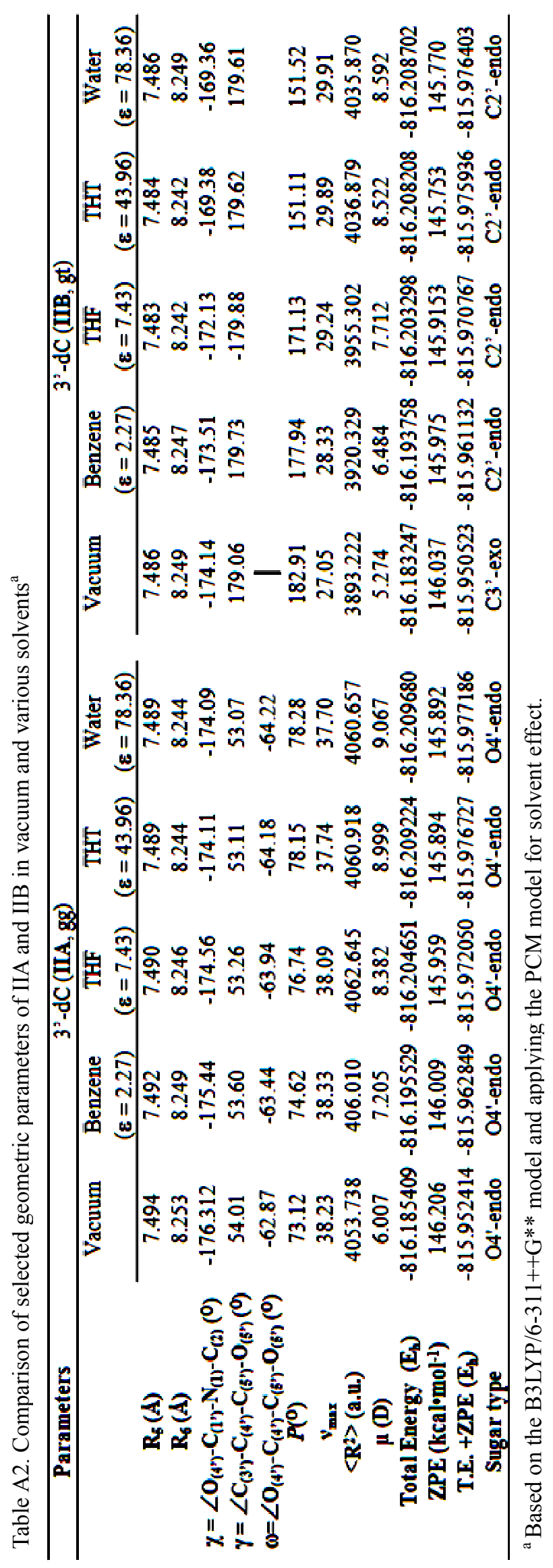

